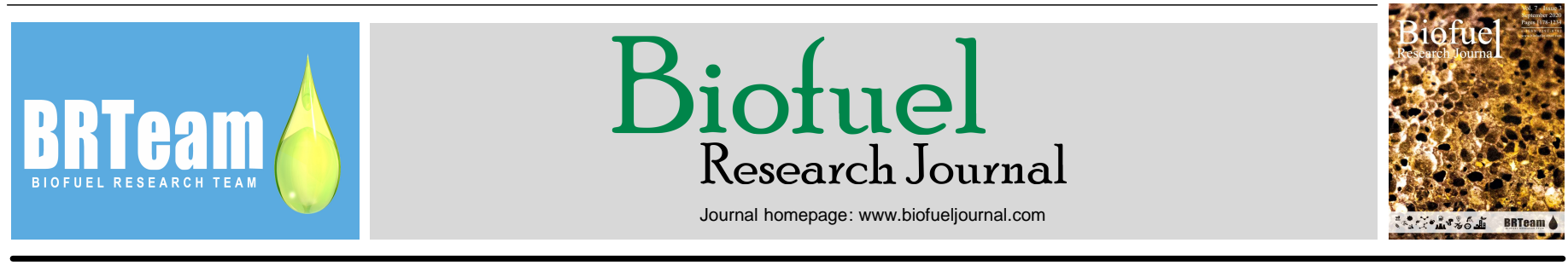

Review Paper

\title{
A review on the role of hierarchical zeolites in the production of transportation fuels through catalytic fast pyrolysis of biomass
}

\author{
Salman Soltanian ${ }^{1,2}$, Chern Leing Lee ${ }^{2, *}$, Su Shiung Lam ${ }^{1, *}$
}

${ }^{I}$ Pyrolysis Technology Research Group, Institute of Tropical Aquaculture and Fisheries (AKUATROP), Universiti Malaysia Terengganu, 21030 Kuala Nerus,

Terengganu, Malaysia.

${ }^{2}$ Chemical Engineering Discipline, Monash University Malaysia, Jalan Lagoon Selatan, 47500 Bandar Sunway, Selangor, Malaysia.

\section{HIGHLIGHTS}

$>$ Impacts of different synthesis strategies of hierarchical zeolites on catalytic pyrolysis of biobased materials are scrutinized.

$>$ Desilication by $0.3 \mathrm{M} \mathrm{NaOH}$ solution is regarded as most suitable procedure for synthesizing hierarchical zeolites.

$>$ Role of metal-modified hierarchical zeolites on catalytic pyrolysis of biomass is reviewed.

Main products of bio-based CFP process over different nonmetallic/metallic hierarchical zeolites are compared to those of parent zeolites.

\section{GRAPHICAL ABSTRACT}

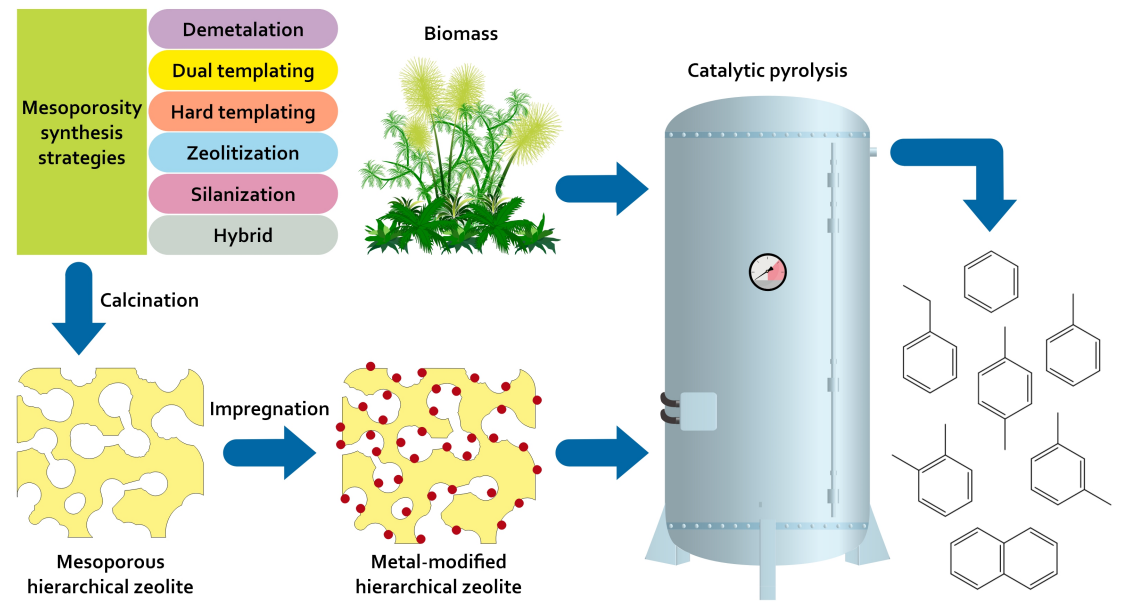

\section{ARTICLE INFO}

\section{Article history:}

Received 8 June 2020

Received in revised form 16 August 2020

Accepted 20 August 2020

Available online 1 September 2020

\section{Keywords:}

Catalytic fast pyrolysis

Hierarchical mesoporous zeolites

Aromatic hydrocarbons

Olefins

Desilication treatment

Metal addition

\begin{abstract}
Design of highly active catalysts plays a critical role in catalytic fast pyrolysis (CFP) of lignocellulosic biomass. Advanced catalysts can improve the deoxygenation rate of pyrolysis vapors and boost the production of fuel precursors. Zeolites are suitable frameworks for catalyzing pyrolysis vapors into species of transportation fuel value. However, their nano-sized structure limits the diffusion of reactants into pores and over active sites. Consequently, the aggregation of large molecules outside micropores leads to a massive coke formation, blocking pore channels, and thus, preventing the accessibility to acid sites. This could cause quick deactivation and instability of the catalyst, necessitating frequent catalyst regeneration and replenishment. Hierarchical micro/mesopore-structured zeolites are promising candidates to cope with the mentioned challenges. In addition to their adjusted pore structure and increased accessibility of acid sites, the formation of mesoporosity in zeolites provides an adequate room for the deposition of additional active phases such as metal nanoparticles, further boosting the catalytic activity. Different strategies used for preparing hierarchical zeolites can tremendously alter their attributes, and consequently affect product selectivity during CFP of biomass. Focusing on the precursors of transportation fuels (i.e., aromatic hydrocarbons and olefins), the present paper critically reviews the impacts of methods used for synthesizing hierarchical zeolite, on CFP of bio-based feedstocks. Moreover, the role of metal addition to hierarchical zeolites in biomass catalytic pyrolysis is also discussed briefly. Among the different synthesis techniques, desilication treatment using alkaline solutions is the most promising owing to its simplicity, high productivity, and scalability. In terms of product selectivity, the addition of Ga species to hierarchical zeolites can increase aromatic hydrocarbons while Ce incorporation can increase the yield of valuable oxygenates such as furan. Despite the advantages of mono-metallic hierarchical zeolites in producing cherished chemicals, future studies should scrutinize the influence of bi-metallic hierarchical zeolites in bio-based CFP processes.
\end{abstract}

(C) 2020 BRTeam. All rights reserved.

Corresponding authors at:

E-mail address: lee.chernleing@monash.edu (Chern Leing Lee) ; lam@umt.edu.my (Su Shiung Lam)

Please cite this article as: Soltanian S., Lee C.L., Lam S.S. A review on the role of hierarchical zeolites in the production of transportation fuels through catalytic fast pyrolysis of biomass. Biofuel Research Journal 27 (2020) 1217-1234. DOI: 10.18331/BRJ2020.7.3.5 


\section{Contents}

1. Introduction.

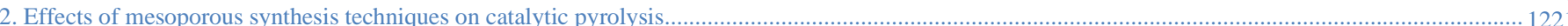

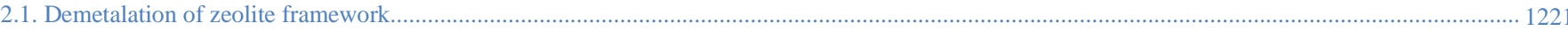

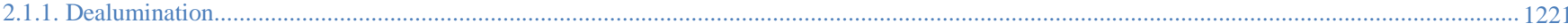

2.1.2. Desilication

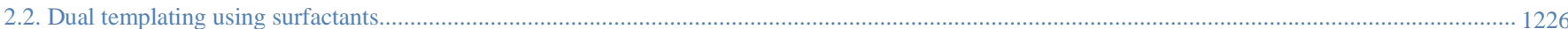

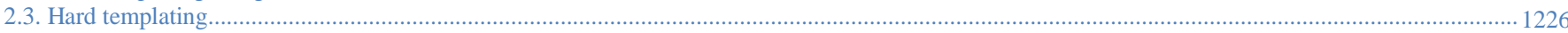

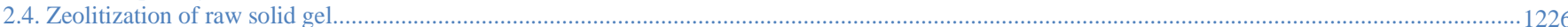

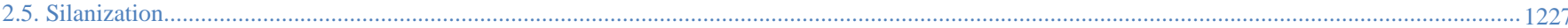

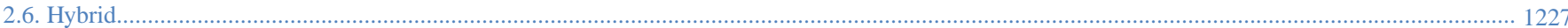

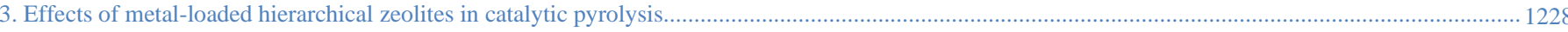

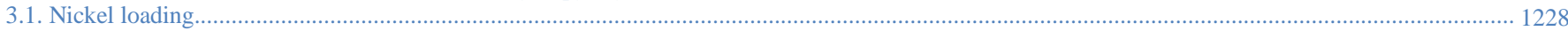

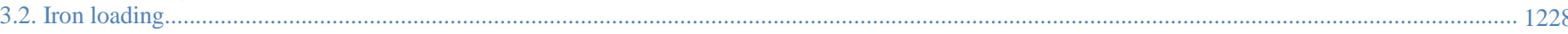

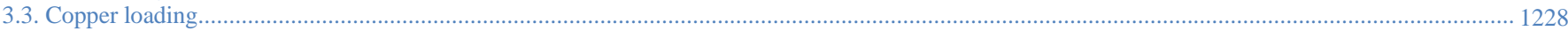

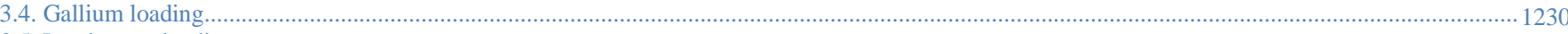

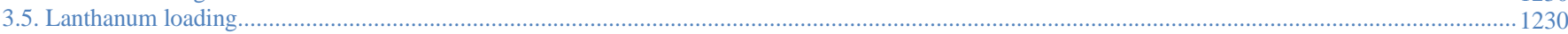

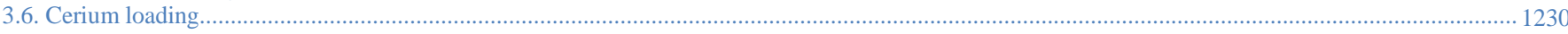

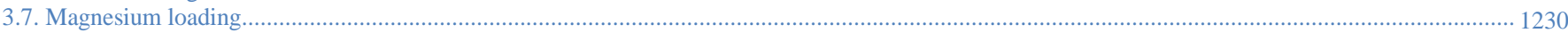

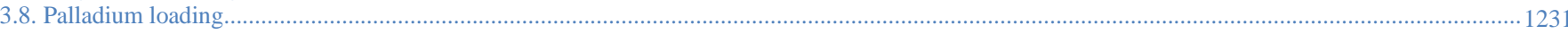

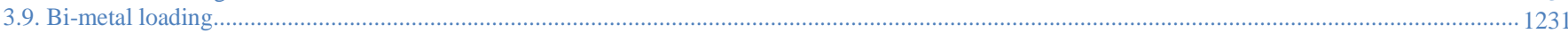

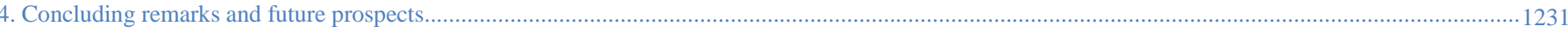

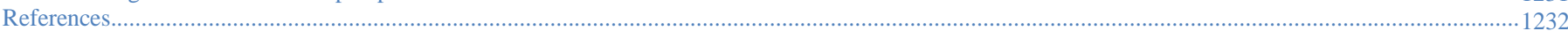

\section{Introduction}

Global modernization, urbanization, and industrialization are accompanied by a substantial expansion of the transportation network and consequently, massive increases in energy demands, mainly met by fossil fuels (Soltanian et al., 2019). These, in turn, have led to increasing emissions of greenhouse gases (mainly carbon dioxide) and the resultant unfavorable phenomena, i.e., global temperature rise and climate change (Soltanian et al., 2020). In this regard, an urgent transition from powering vehicles by fossil-based fuels to more environmentally-friendly alternatives such as electricity generated by wind, solar, and hydro technology is of crucial importance. However, the apparent shortcomings of battery technologies in terms of capacity and charging time hinder the reliable use of clean electricity in vehicles. Hence, liquid biofuels are still considered as promising options for substituting fossil fuels in the transportation sector (Abdullah et al., 2019).

There are three main strategies for converting biomass into fuel precursors including chemical routes (e.g., transesterification), biological routes (e.g., aerobic digestion, anaerobic digestion, fermentation), and thermochemical routes (e.g., hydrothermal liquefaction, fast/slow pyrolysis, gasification) (Tabatabaei et al., 2019). Among all conversion methods, fast pyrolysis is a highly reliable approach for transforming low-grade biomass into liquid bio-oil (up to $75 \mathrm{wt} \%$ ) with a higher energy density (Aghbashlo et al., 2019). Fast pyrolysis refers to the thermal degradation of biomass into condensable vapors at temperatures ranging between $400-600{ }^{\circ} \mathrm{C}$ in the limited presence of oxygen for short residence times of 1-2 seconds (Álvarez-Chávez et al., 2019). Then, the pyrolytic vapors are immediately cooled down to obtain a thermally unstable black liquor also known as bio-oil (Aghbashlo et al., 2019).

It should be noted that the bio-oil derived from fast pyrolysis is not suitable to be used directly as transportation fuel and is not miscible to be blended partially either (Liu et al., 2014). Table 1 proves the dissimilarities between fossil crude oil and bio-oil. Pure bio-oil suffers from high viscosity, intense corrosivity, poor chemical stability, and relatively low heating value (Tabatabaei et al., 2019). Many undesirable compounds are to blame for these adverse attributes primarily including oxygenates (e.g., aldehydes, ketones), carboxylic acids (e.g., acetic acid, propionic acid), unsaturated species, oligomers, and water (Liu et al., 2014). Figure 1 shows the typical chemical constituents of bio-oil and their relative contents along with their classifications according to functional groups. Overall, it has been reported that bio-oil encompasses more than 300 unfavorable species (Tan et al., 2018). In this regard, it is imperative to deoxygenate and stabilize the produced bio-oil before further processing for the production of on-specified transportation fuels.

Compared to non-catalytic fast pyrolysis, catalytic fast pyrolysis (CFP) is a promising technique resulting in improved bio-oil characteristics. Through CFP, hot pyrolytic vapors meet a catalyst bed before condensing into the liquid
Table 1.

A comparison between the typical characteristics of crude oil and bio-oil*

\begin{tabular}{lcc}
\hline Parameter & Crude oil & Bio-oil \\
\hline Paraffins (wt\%) & 40.11 & $18-38$ \\
Naphthenes (wt\%) & 37.83 & $\mathrm{NA}$ \\
Olefins (wt\%) & $\mathrm{NA}$ & $53-69$ \\
Aromatics (wt $\%)$ & 22.06 & $8-13$ \\
Oxygenates (wt\%) & $\mathrm{NA}$ & $28-34$ \\
Water (wt\%) & 0.1 & $15-33$ \\
Insoluble solids (wt\%) & 0.5 & 0.01 \\
Ash (wt\%) & 0.1 & $<0.2$ \\
$\mathrm{C}(\mathrm{wt} \%)$ & 83.86 & $45-66$ \\
$\mathrm{H}(\mathrm{wt} \%)$ & $11-14$ & $5-11$ \\
$\mathrm{O}(\mathrm{wt} \%)$ & $<1$ & $26-45$ \\
$\mathrm{~S}(\mathrm{wt} \%)$ & $<4$ & $<0.05$ \\
$\mathrm{~N}(\mathrm{wt} \%)$ & $<1$ & $<0.4$ \\
pH & $\mathrm{NA}$ & $2.5-3.8$ \\
Density $\left(\mathrm{g} \mathrm{ml}^{-1}\right)$ & $0.86-0.94$ & $1.05-1.30$ \\
Viscosity at $50{ }^{\circ} \mathrm{C}(\mathrm{cP})$ & 180 & $40-110$ \\
$\mathrm{HHV}\left(\mathrm{MJ} \mathrm{kg}{ }^{-1}\right)$ & 44 & $16-21$ \\
\hline
\end{tabular}

NA: Not available

* Source: Pyl et al. (2011); Dickerson and Soria (2013); Önal et al (2014); Bertero and Sedran (2016); Olarte et al. (2017); Shi et al (2017); Ibarra-Gonzalez and Rong (2019); Mondal et al. (2020)

phase. The advantages and disadvantages of CFP over non-catalytic fast pyrolysis are presented in Table 2. Generally, the CFP technologies are categorized into ex-situ CFP or in-situ CFP; the former is a strategy in which the pyrolysis and upgrading stages are separated by using the catalys bed at the downstream of the pyrolysis reactor while the latter is a technique in which the pyrolysis process is interwoven with an upgrading step by mixing the feedstock with catalyst before heating (Zhang et al., 2016). Table 3 presents the merits and drawbacks of these CFP types.

A major problem associated with using catalyst in biomass fast pyrolysis is the massive coke deposition on the surface of the catalyst causing its rapid deactivation. Thus, it is of crucial significance to design suitable catalysts leading to increased yields of aromatics while reducing coke formation. In light of that, substantial efforts have been put into exploring high-performance catalysts for the CFP of biomass, among which, zeolites have gained a particular prominence. As an important attribute, zeolitic materials possess a high level of crystallinity imparting a high thermal/hydrothermal stability to them. Typically, the structures of zeolites are composed of cavities and channels, 0.3 and $1.5 \mathrm{~nm}$ in size (Groen et al., 2007). 


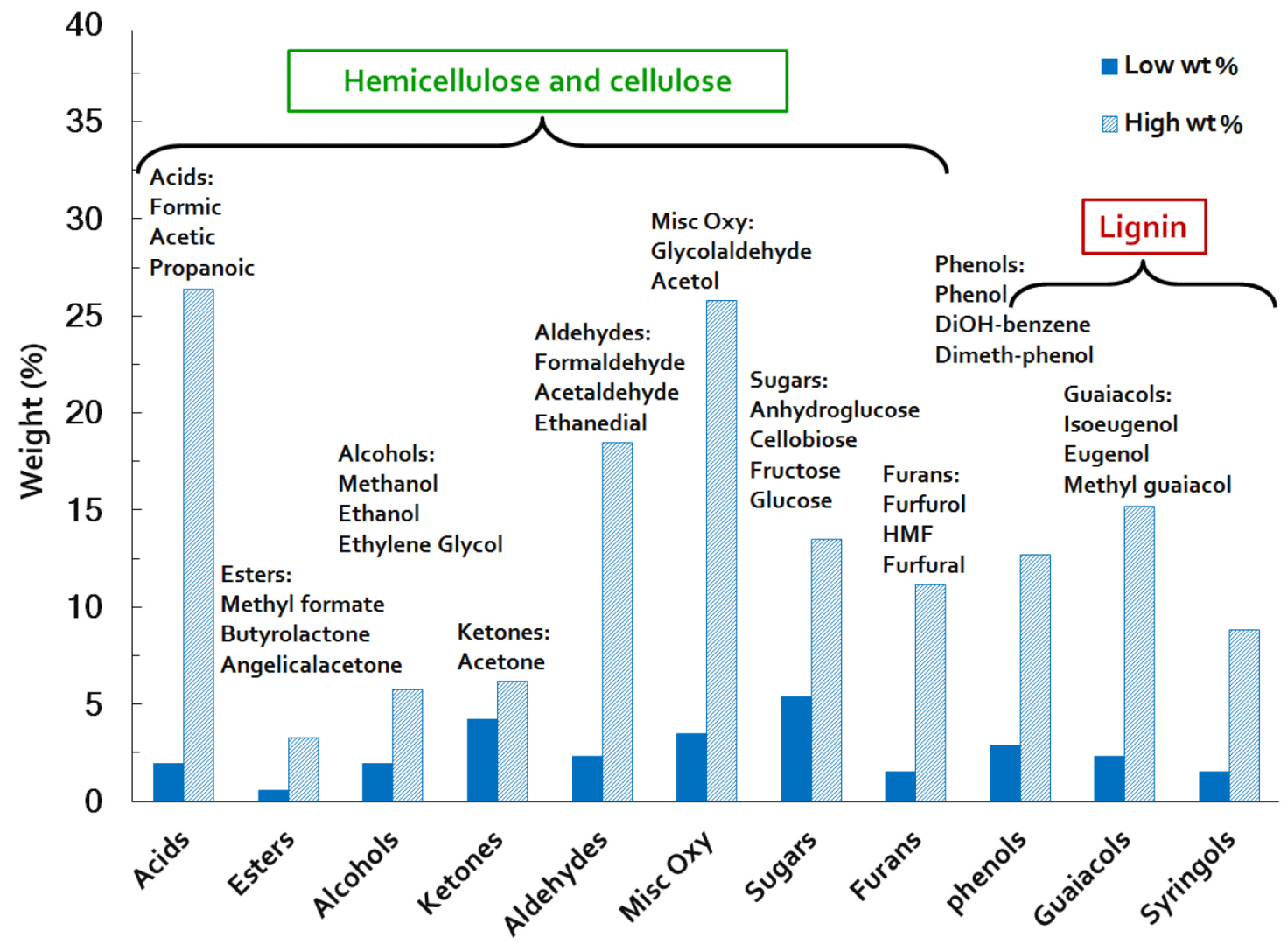

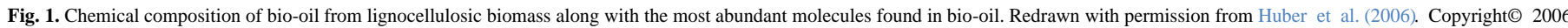
American Chemical Society.

Table 2.

Merits and drawbacks of catalytic fast pyrolysis compared to its non-catalytic counterpart*.

\begin{tabular}{ll}
\hline Advantages & Disadvantages \\
\hline - Single reactor & \\
- High compatibility of the produced bio-oil with & \\
existing infrastructures & \\
- Lower reaction temperature & • High energy consumption \\
- High-grade bio-oil and its diverse applications & $\bullet$ Catalyst cost \\
- High stability and energy density of final liquid & • Need for catalyst regeneration \\
products & • Unreliable re-usage of \\
- High adsorption properties of the produced char for & deactivated catalyst \\
removing heavy metals, contaminants, pollutants, & \\
and odor from wastewater/polluted air & \\
necreased impurities (e.g., solid residue, sulfur, & \\
\hline nitrogen, phosphorous) in the produced liquid oil &
\end{tabular}

It is important to note that zeolites are shape-selective as they have uniform passages within the micropore range. Thus, they are capable of separating different molecules according to their shapes and sizes. This characteristic of zeolites renders them suitable adsorbents in separation processes. In addition, zeolites possess a high ion-exchange capability owing to the presence of aluminium atoms in their structure which impose negative charges on the framework that could be compensated by external cations. This feature of zeolites is well exploited in different industries such as water treatment and detergent manufacturing. It is worthwhile to note that the transferable cations
Table 3.

The pros and cons of different types of CFP, i.e., in-situ CFP and ex-situ CFP*.

\begin{tabular}{|c|c|c|}
\hline CFP type & Merits & Drawbacks \\
\hline In-situ CFP & $\begin{array}{l}\text { - Intimate contact between feedstock } \\
\text { and catalyst } \\
\text { - Higher rate of biomass conversion } \\
\text { into liquid products (especially } \\
\text { aromatics) } \\
\text { - Lower capital cost owing to the } \\
\text { simpler process configuration }\end{array}$ & $\begin{array}{l}\text { - Catalyst deterioration due to its } \\
\text { exposure to char and ash } \\
\text { - Complex separation of catalyst } \\
\text { from char and ash } \\
\text { - Higher poisoning of the catalyst } \\
\text { through the accumulation of } \\
\text { metals }\end{array}$ \\
\hline Ex-situ CFP & $\begin{array}{l}\text { - Ability to keep the catalyst separate } \\
\text { from contaminants } \\
\text { - Simple regeneration and reuse of } \\
\text { catalyst } \\
\text { - Ability to perform thermal and } \\
\text { catalytic stages at different } \\
\text { temperatures } \\
\text { - Superior control on bio-oil yield and } \\
\text { its composition } \\
\text { - Higher deoxygenation activity } \\
\text { compared to in-situ pyrolysis } \\
\text { - Lower techno-economic risk } \\
\text { compared to in-situ }\end{array}$ & $\begin{array}{l}\text { - Higher minimum fuel-selling } \\
\text { price compared to in-situ CFP }\end{array}$ \\
\hline
\end{tabular}

* Source: Li et al. (2015); Murugappan et al. (2016); Iisa et al. (2016); Kumar et al. (2019) 
of zeolites could be replaced by protons, acting as robust Brønsted acid sites. On the other hand, Lewis acid sites could be formed through dehydroxylation of these protons. In this regard, the high and tunable acidity of zeolites makes them highly attractive as catalyst in petrochemical and oil industries (Primo and Garcia, 2014). In addition, zeolites are good candidates to be used as support for additional active phases based on which advanced bifunctional catalysts could be prepared through metal incorporation.

In the CFP process, zeolitic materials are capable of deoxygenating the vapors through dehydration, cracking, isomerization, cyclization, and aromatization reactions to produce high amounts of deoxygenated species (Mihalcik et al., 2011; lisa et al., 2016). The shape selectivity and acidity of zeolites are determining factors in the thermal conversion of biomass into valuable products. Jae et al. (2011) found that the aromatic yields from the CFP of glucose over different zeolites formed a bell-shaped trend as a function of zeolite pore size. They showed that zeolites with small pores (i.e., SAPO-34, ZK-5) favored the production of oxygenates and coke instead of aromatics, while zeolites with medium pore sizes (i.e., SSZ-20, ZSM-11, ZSM-5, IM-5, TNU-9) yielded the highest amounts of aromatics. The zeolites with large pore sizes (i.e., SSZ-55, $\beta$ zeolite, Y zeolite) tended to form low aromatics, high coke, and low oxygenates.

However, the small pores of microporous zeolites pose a critical problem in the CFP of biomass as they prevent the diffusion of bulky biopolymers into the micropores. In this context, the majority of active sites, that are placed inside the zeolite micropores, are barely reachable by the reactants. Even worse, the aggregation of biopolymeric molecules on the exterior surface of microporous zeolites could result in high coke formation at elevated temperatures, blocking the micropores, and consequently, limiting further access of the reactants to the acid sites inside the micropores (Chen et al., 2018a). Therefore, conventional microporous zeolites could not be exploited for their highest catalytic potentials and suffer from low activities.

It should be noted that many of the oxygen-containing volatiles produced during the biomass fast pyrolysis cannot penetrate into the zeolite micropores and as a result, they re-polymerize to form the coke precursors on the external surface of the catalyst (Stanton et al., 2018). For instance, the dimensions of the syringol and guaiacol molecules, as representatives of lignin-derived compounds, are $10.738 \times 7.856 \times 4.218 \AA$ and $9.476 \times 8.101 \times 4.197 \AA$, respectively. On the other hand, ZSM-5 zeolite has a three-dimensional pore structure consisting of two perpendicularly intersecting channels of 10 membered rings, i.e., straight channels $(5.5 \times 5.1 \AA)$ and zigzag channels $(5.6 \times 5.3 \AA)$. Consequently, the lignin-derived bulky oxygenated compounds produced during lignin catalytic pyrolysis could not diffuse into the microporous pores of the ZSM-5 zeolite, leading to high coke formation and thus catalyst deactivation. It should be noted that although the deactivated catalyst could be regenerated through combustion in an air environment, the low-temperature combustion might not satisfactorily remove the coke while the combustion at high temperature could overheat the catalyst which might further lead to its structure collapse (Shao et al., 2016).

In the past years, hierarchical zeolites consisting of two porosity levels (i.e., microporous and mesoporous structures) have been shown as a promising remedy to address the small pore scale of conventional zeolites. These zeolites enhance the accessibility of reactants to the internal acid sites, resulting in higher catalytic activities in the reactions suffering from steric and diffusional limitations (Serrano and Pizarro, 2013). Chang et al. (2013) observed that the introduction of the mesoporosity could appreciably reduce the diffusional time constants of cyclohexane into hierarchical silicalite-1, indicating facile mass transport and rapid overall adsorption/desorption.

Facilitated reachability to Brønsted acid sites on the mesopore surface promotes the rates of decarbonylation reactions to produce aromatic-enriched bio-oils (Puértolas et al., 2015). In this context, Jia et al. (2017) showed that the formation of both mono-aromatic and bi-aromatic hydrocarbons over the hierarchical zeolites are faster than over their parent zeolites. This is ascribed to the fact that the diffusion of reactants onto active sites inside the mesopores, as well as the diffusion of products out of the zeolite particles, become faster after the hierarchicalization of parent zeolite microporosity. Similarly, Stanton et al. (2018) revealed that the hierarchical mesoporous ZSM-5 could boost the formation of mono-aromatic hydrocarbon, olefins, alkanes, and normal phenol, while its microporous counterpart tended to produce poly-aromatic hydrocarbons.
It is notable that the molecular diffusion within the micropores primarily follows the configurational or restricted diffusion mechanism; whereas, the diffusion of molecules inside secondary mesopores complies with the Knudsen diffusion mechanism (Li et al., 2014b). It is important to note that the secondary mesoporosity shortens the diffusion length substantially. On another hand, the diffusion rate varies with the inverse of the square of the diffusion length. Therefore, the diffusion time in hierarchical frameworks are more than two orders of magnitude shorter than those in microporous structures (Groen et al., 2007). It is worth mentioning that temperature has a remarkable impact on the diffusivities of substrate molecules in hierarchical zeolites. Bu et al. (2018) demonstrated that the diffusion inside the microporosity and along the outer surface of hierarchical mesoporous H-ZSM-5 zeolite is favorable only at low temperatures, while the diffusion within the mesoporosity is considerably improved at typical pyrolysis temperatures. Nevertheless, it has been perceived that an appropriate tradeoff between mesoporosity and microporosity is imperative for yielding high aromatics. In addition, the distribution of aromatic compounds is correlated strongly with the microporosity (Qiao et al., 2019).

The presence of mesoporous crystals interconnecting with micropores could assist with diffusing much of coke precursors out of the micropores, preventing the micropore blockage that would otherwise cause catalyst deactivation (Escola et al., 2012). Although the coke precursors might then be deposited on the mesoporous mouths or the exterior catalyst surface, they impose much less harmful effects on the stability of the catalyst (Jia et al., 2017). For this reason, unlike microporous zeolites, much of the activity could be recovered after the regeneration of hierarchical zeolites. Moreover, the hierarchical zeolites could markedly reduce the burning temperature of the regeneration, alleviating the problem of overheating in the microporous zeolites (Fig. 2)

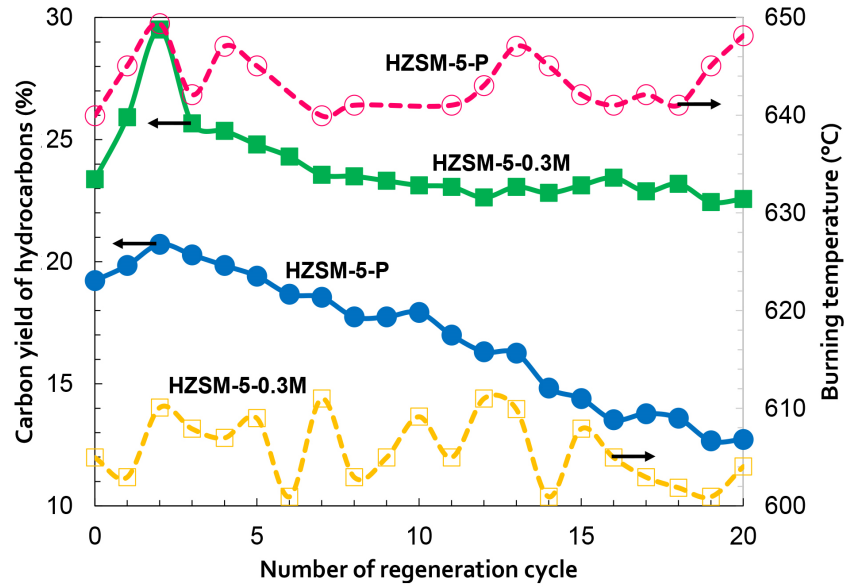

Fig. 2. Carbon yield of hydrocarbons and burning temperature as a function of the number of regeneration cycles for parent $(\mathrm{P})$ and hierarchical (0.3M) HZSM-5 zeolites. Redrawn with permission from Shao et al. (2016). Copyright@ 2016 Royal Society of Chemistry (License ID: 1058135-1)

In the CFP process, incorporating metals into the zeolitic framework is well-recognized as a successful tactic for alleviating the catalys deactivation as a result of surface coke formation and for enhancing the selectivity towards hydrocarbons and less oxygenated chemicals. There have been plenty of studies attempting to introduce different metallic cations as non-framework species in interaction with zeolite acid sites to improve bio-oil characteristics. For example, Cheng et al. (2012) showed that bifunctional Ga-loaded HZSM-5 catalysts could produce aromatic hydrocarbons up to $40 \%$ higher compared with the conventional ZSM-5 zeolite. The increased aromatics is due to the fact that the Ga species promoted decarbonylation and olefin aromatization reactions, while the ZSM-5 fraction catalyzed the cracking and oligomerization reactions.

Mullen et al. (2018) reported that Ga-doped ZSM-5 zeolites favored the production of aromatics through the olefin oligomerization and 
aromatization reactions when the biomass-to-catalyst ratio was increased by up to 1.5 folds. Sun et al. (2016) demonstrated that the Fe-incorporated ZSM-5 had a superior activity in converting the oxygenated species into monocyclic aromatic hydrocarbons than its Fe-free counterpart. They observed that the FeZSM-5 zeolite is associated with reduced formation of coke precursors through hindering the re-polymerization of monocyclic aromatic hydrocarbons and other oxygenates. Liang et al. (2017) revealed that the ZSM-5 zeolites loaded with $\mathrm{Ni}, \mathrm{Co}$, and $\mathrm{Zn}$ increased aldehydes, ketones, and phenols in the bio-oil.

However, the dispersity of metal species in the microporous zeolite is not sufficient for achieving completely favorable performances. Unlike the deposition of promoters (i.e., metal nanoparticles) on the external surface of microporous zeolites, the secondary mesoporosity in the hierarchical zeolites imparts a striking opportunity for enhancing the dispersion of metals into the porous structure. The synthesis strategy for creating secondary mesoporosity plays a determining role in the stability, activity, and lifetime of hierarchical zeolites. Accordingly, the present review provides a critical overview on the impacts of different synthesis strategies on the CFP of bio-based feedstock. Moreover, the role of the metal incorporation into hierarchical zeolite frameworks is discussed. Overall, the present work is aimed at shedding light on the importance of hierarchical mesoporous zeolites in the catalytic pyrolysis.

\section{Effects of mesoporous synthesis techniques on catalytic pyrolysis}

Typically, there are two main synthesis classifications for constructing mesopores in zeolites including (a) top-down strategy and (b) bottom-up strategy. In the top-down technique, the mesoporosity is incorporated through post-synthetic approaches, such as desilication using the alkaline treatment, dealumination by steaming or the acid treatment, and desilication in the presence of a surfactant or a pore directing agent. In the bottom-up technique, a hydrothermal synthesis (direct technique), such as carbon templating and seed silanization, is applied for the formation of mesopores over zeolites. The postsynthesis methods form intracrystal mesopores while the direct techniques build mesoporous zeolite fragments (Chen et al., 2014).

\subsection{Demetalation of zeolite framework}

The post-synthesis of zeolites through the demetalation of their framework is a simple and productive strategy for introducing mesopores into microporous zeolites through which the elements of the zeolite framework (aluminium and silicon) can be extracted selectively. The withdrawal of these elements from the zeolite crystals results in mesoporosity. As a major defect of the demetalation strategy, a substantial portion of the zeolite bulk is inevitably lost through dissolution by the treatment agents. Depending on the metal removed from the structure, the formed mesoporosity possesses different characteristics. Therefore, the demetalation method and conditions play crucial roles in the performance of the CFP process. In the following subsections, different classes of demetalation post-synthesis are concisely presented and their impacts on the CFP of bio-based substrates are discussed.

\subsubsection{Dealumination}

Dealumination is a suitable post-synthesis technique to induce mesoporosity in zeolites with lower $\mathrm{Si} / \mathrm{Al}$ ratios, such as FAU and ultra-stable Y-type (USY) zeolites. In this method, the aluminium atoms are removed from the zeolite framework using a hydrothermal treatment or by chemical agents. The treatment by acid solutions at high temperatures is the most familiar procedure for the removal of aluminums (Feliczak-Guzik, 2018). Although the dealumination method could stabilize the structure of zeolites by improving the $\mathrm{Si} / \mathrm{Al}$ ratio, it also partially damages the zeolite structure and forms unfavorable voids in the framework (Khan et al., 2019). In addition, the withdrawal of aluminum atoms could lead to a massive loss of acid sites of the zeolite, weakening its catalytic activity for cracking and aromatization Therefore, the hierarchical mesoporous zeolites prepared by dealumination treatment are not suitable candidates for use in the CFP process. Accordingly, other demetalation techniques, such as desilication method or sequential dealumination and desilication, are regarded as more advantageous compared with the application of the dealumination method alone (Wang et al., 2017).

\subsubsection{Desilication}

The desilication is an effective method for forming mesoporosity inside conventional zeolites, especially those with high $\mathrm{Si} / \mathrm{Al}$ ratios such as ZSM5 zeolite, as it preserves structural integrity. In this method, some silica atoms are removed from the crystal framework with alkali solutions. Generally, the $\mathrm{Si}-\mathrm{O}-\mathrm{Al}$ linkages are barely hydrolyzed in alkali solutions owing to the negative charge of the $\mathrm{AlO}_{4}^{-}$preserving the four-coordinated $\mathrm{Al}$ from $\mathrm{OH}^{-}$attack. As a result, the $\mathrm{Si}$ atoms next to the four-coordinated $\mathrm{Al}$ are also secured from the attack of hydroxide anions. Hence, the alkaline solutions favor the breakage of the $\mathrm{Si}-\mathrm{O}-\mathrm{Si}$ linkages not neighboring the four-coordinated Al, and form terminal Si-OH (Fig. 3) (Svelle et al., 2011). It should be noted that a small extent of dealumination is unavoidable for the zeolites with low $\mathrm{Si} / \mathrm{Al}$ ratios due to their high $\mathrm{Al}$ content.
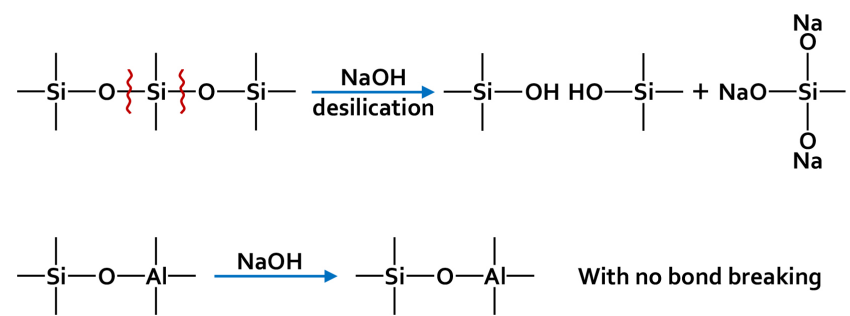

Fig. 3. Mechanism of bond scission using alkaline treatment. Redrawn with permission from Ren et al. (2018). Copyright@ 2018 American Chemical Society.

The removal of Si atoms from the zeolite framework creates structural defects in the lattice. However, the exact morphology of alkali-treated hierarchical zeolites is substantially dependent on the treatment conditions. As an influential factor, the concentration of alkali solution used has a striking impact on the structure of the formed mesoporosity. After treatment by an alkaline solution, the mesopore volume is largely increased at the expense of a reduction in micropore surface and volume, indicating the reform of micropores into mesopores (Table 4). For low alkaline concentrations, the surface and volume of micropores are decreased slightly, while high concentrations lead to notable reductions in microporosity.

Table 4.

Physical characteristics of parent ZSM-5 zeolite and the hierarchical ZSM-5 zeolites treated by different NaOH solutions (0.2-0.8 M)*

\begin{tabular}{|c|c|c|c|c|c|c|c|c|}
\hline \multirow{2}{*}{ Catalyst type } & \multirow{2}{*}{$\mathrm{Si} / \mathrm{Al}$ ratio } & \multicolumn{3}{|c|}{ Specific surface area $\left(\mathrm{m}^{2} / \mathrm{g}\right)$} & \multicolumn{2}{|c|}{ Pore volume $\left(\mathrm{cm}^{3} / \mathrm{g}\right)$} & \multirow{2}{*}{ Hierarchy factor, $\mathbf{H F}^{\mathbf{a}}$} & \multirow{2}{*}{ Relative crystallinity (\%) } \\
\hline & & $\mathbf{S}_{\text {BET }}$ & $\mathbf{S}_{\mathrm{ex} / \mathrm{mes}}$ & $\mathbf{S}_{\text {micro }}$ & $\mathbf{V}_{\text {meso }}$ & $\mathbf{V}_{\text {micro }}$ & & \\
\hline ZSM-5 (parent) & 54.0 & 357.2 & 39.0 & 318.2 & 0.035 & 0.134 & 0.0866 & 85.70 \\
\hline ZSM-5 (0.2 M) & 53.5 & 407.1 & 138.9 & 268.1 & 0.226 & 0.104 & 0.1075 & 100.00 \\
\hline ZSM-5 (0.3 M) & 46.3 & 446.6 & 261.7 & 184.9 & 0.258 & 0.082 & 0.1413 & 86.85 \\
\hline ZSM-5 (0.5 M) & 31.9 & 337.5 & 198.1 & 139.4 & 0.217 & 0.065 & 0.1353 & 64.94 \\
\hline ZSM-5 (0.8 M) & 20.3 & 271.2 & 176.0 & 95.2 & 0.178 & 0.046 & 0.1333 & 59.29 \\
\hline
\end{tabular}

${ }^{\mathrm{a}}$ The hierarchy factor $(\mathrm{HF})=\left(\mathrm{V}_{\text {micro }} / \mathrm{V}_{\text {pore }}\right) \times\left(\mathrm{S}_{\text {meso }} / \mathrm{S}_{\mathrm{BET}}\right)$.

* Reproduced with permission from Chen et al. (2014). Copyright@ 2014 American Chemical Society. 
Micropore

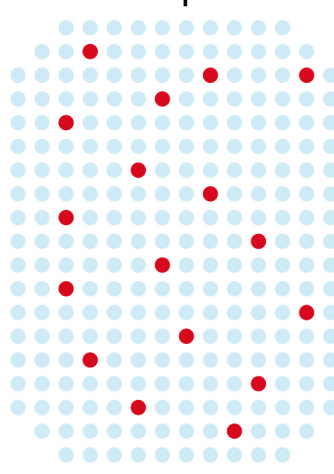

A Si

\section{Framework collapsing}

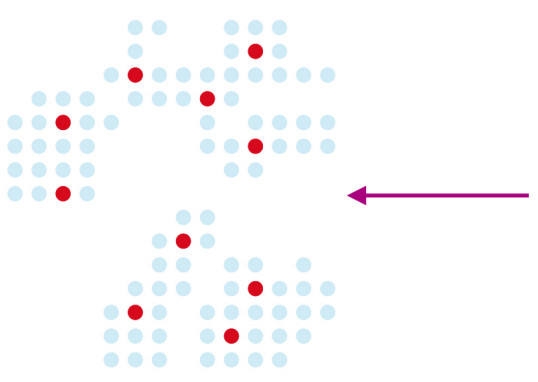

Sheet-like mesopore

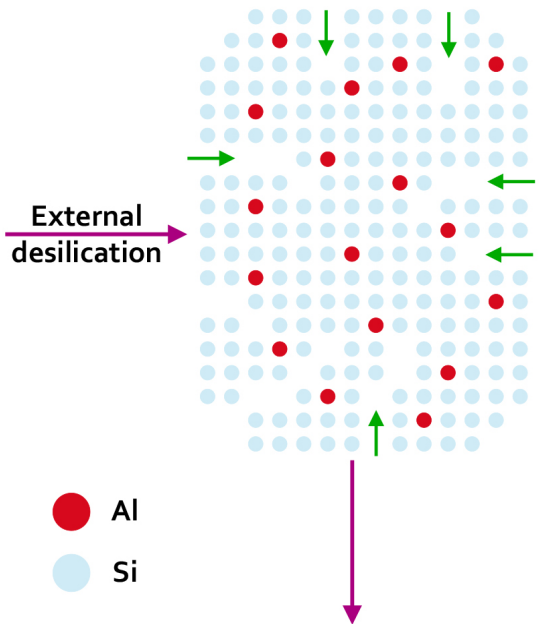

Hollow mesopore

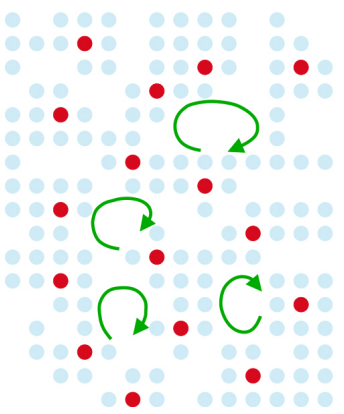

Fig. 4. Steps of mesopore formation in HZSM-5 by alkaline desilication. Redrawn with permission from Shao et al. (2016). Copyright $\odot 2016$ Royal Society of Chemistry (License ID: 1058135-1).

In more detail, moderate alkali concentrations generate sheet-like pores only on the outer sphere, while alkali solutions with higher intensities could simply diffuse into the internal space leading to severe corrosion and consequently, the formation of hollow mesopores (Fig. 4). Excessive alkali treatments could result in the framework collapse and uncontrolled loss of acid sites. In this context, Xiao et al. (2015) showed that the hierarchical HZSM-5 zeolites desilicated with the $\mathrm{NaOH}$ solutions with concentrations lower than $0.4 \mathrm{M}$ generated considerable mesopores as they maintained an adequate level of microporosity. In these cases, the crystallinity of the hierarchical zeolites did not change significantly. While $\mathrm{NaOH}$ solutions with concentrations higher than 0.5 decreased the relative crystallinity of the zeolites, consequently shortening the lifetime of the catalysts. The decrease in relative crystallinity is likely ascribed to the decrease in bulk $\mathrm{Si}-\mathrm{O}-\mathrm{Si}$ bonds and the increase in surface atoms with growing mesoporosity (Hoff et al., 2017). Moreover, high concentrations of $\mathrm{NaOH}$ could break $\mathrm{Si}-\mathrm{O}-\mathrm{Al}$ bonds in addition to $\mathrm{Si}-\mathrm{O}-\mathrm{Si}$ bonds, leading to both dealumination and desilication of zeolite framework. Figure 5 displays the TEM images of parent microporous HZSM- 5 zeolite and hierarchical HZSM-5 zeolites desilicated with different $\mathrm{NaOH}$ concentrations in order to understand the effect of alkali intensity on mesoporosity formation and mesopore size distribution.

It has been reported that alkaline desilication transforms Brønsted acid sites into Lewis acid sites meaning that alkali treatments with higher concentrations result in greater losses in Brønsted acidity (Table 5) (Xiao et al., 2015). This might be related to the elimination of internal $\mathrm{Si}-\mathrm{OH}$ bonds from zeolite framework as well as the retention of extracted aluminium atoms on the outer surface of the zeolite. Therefore, product distribution and selectivity during CFP could considerably vary with alkali intensification. Table 6 tabulates the changes in yields of the main products of bio-based CFP process (i.e., oxygenates, aromatics, olefins, and coke) over different nonmetallic
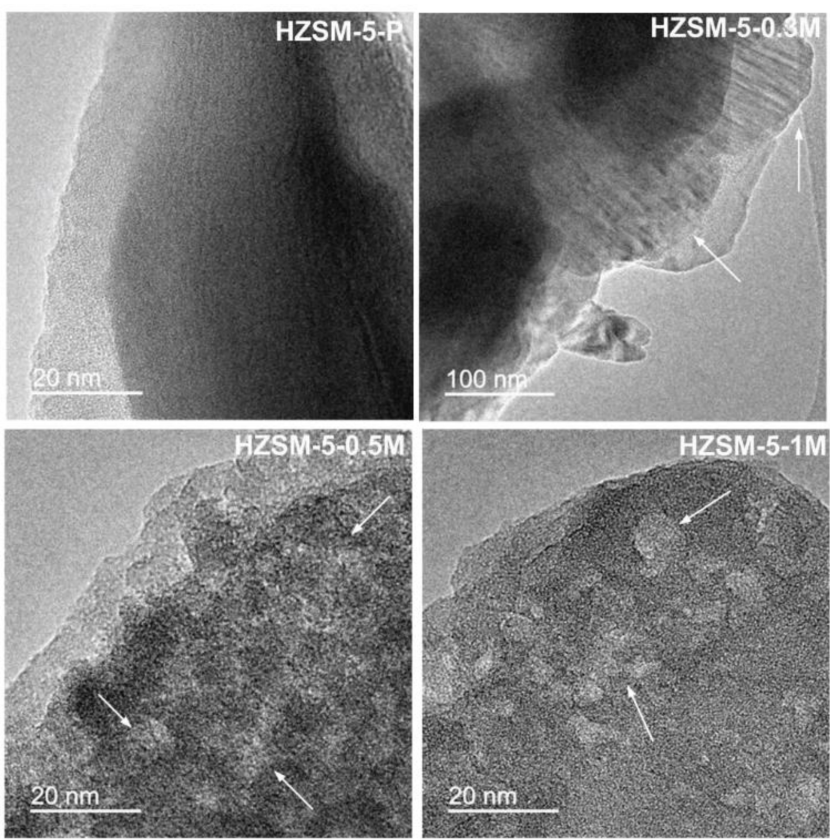

Fig. 5. TEM images of parent microporous HZSM-5 zeolite and hierarchical HZSMzeolites desilicated with $0.3,0.5$, and $1.0 \mathrm{M} \mathrm{NaOH}$ solutions. Reprinted with permission from Shao et al. (2016). Copyright $\odot 2016$ Royal Society of Chemistry (License ID: 1058135-1).

Table 5.

The acidities associated with parent HZSM-5 zeolite and the hierarchical HZSM-5 zeolite treated by different $\mathrm{NaOH}$ solutions $(0.1-0.7 \mathrm{M})$. The acidities of all the catalysts were measured by pyridine-IR spectra*

\begin{tabular}{lccc}
\hline \multirow{2}{*}{ Catalyst type } & \multicolumn{3}{c}{ Acidity (mmol/g) } \\
\cline { 2 - 4 } & Brønsted acid (B) & Lewis acid (L & B/L \\
\hline HZSM-5 (parent) & 0.173 & 0.271 & 0.638 \\
HZSM-5 (0.1 M) & 0.157 & 0.281 & 0.559 \\
HZSM-5 (0.2 M) & 0.132 & 0.287 & 0.460 \\
HZSM-5 (0.3 M) & 0.109 & 0.290 & 0.376 \\
HZSM-5 (0.4 M) & 0.076 & 0.313 & 0.243 \\
HZSM-5 (0.5 M) & 0.063 & 0.332 & 0.190 \\
HZSM-5 (0.7 M) & 0.049 & 0.341 & 0.144 \\
\hline
\end{tabular}

* Source: Reproduced with permission from Xiao et al. (2015). Copyright $\odot 2015$ Royal Society of Chemistry (License ID: 1058139-1).

hierarchical zeolites (prepared by different synthesis methods) in comparison with their microporous counterparts. Li et al. (2014a) revealed that the hierarchical ZSM-5 desilicated with $0.3 \mathrm{M} \mathrm{NaOH}$ attained the highest amount of aromatics (i.e., 30.2\%) and lowest coke formation (i.e., $39.9 \%$ ) during the CFP of beech wood. On the contrary, the zeolite treated with the high $\mathrm{NaOH}$ concentration of $0.5 \mathrm{M}$ remarkably reduced the aromatic production as the treatment ruined a large fraction of its microporosity. Similarly, Ding et al. (2017) confirmed that the hierarchical HZSM-5 zeolite desilicated by $0.3 \mathrm{M} \mathrm{NaOH}$ solution, as the optimal catalyst, augmented aromatic yields by $44 \%$ and mitigated coke deposition by $29 \%$ compared with the parent zeolite. Moreover, this hierarchical catalyst increased the selectivity towards BTX compounds (i.e., benzene, toluene, and xylenes) by $82 \%$. Shao et al. (2016) also evidenced that the catalytic pyrolysis of furan yielded the highest amounts of aromatic hydrocarbons and olefins over the hierarchical zeolite desilicated with 0.3 
Table 6.

The changes in yields of the main products of bio-based CFP process over different nonmetallic hierarchical zeolites prepared by different synthesis methods.

\begin{tabular}{|c|c|c|c|c|c|c|c|c|c|}
\hline $\begin{array}{l}\text { Zeolite } \\
\text { framework }\end{array}$ & Synthesis method & $\begin{array}{c}\mathrm{Si} / \mathrm{Al} \text { of } \\
\text { synthesized } \\
\text { zeolite }\end{array}$ & Feedstock (s) & $\begin{array}{l}\text { Operating } \\
\text { conditions }\end{array}$ & $\begin{array}{l}\text { Change in } \\
\text { oxygenates } \\
\text { yield }\end{array}$ & $\begin{array}{l}\text { Change in aromatic } \\
\text { hydrocarbons yield }\end{array}$ & $\begin{array}{c}\text { Change in olefins } \\
\text { yield }\end{array}$ & $\begin{array}{l}\text { Change in coke } \\
\text { formation }\end{array}$ & Reference \\
\hline ZSM-5 & $\begin{array}{l}\text { Desilication by } 0.1-0.5 \\
\mathrm{M} \mathrm{NaOH} \text { solution }\end{array}$ & $21.1-25.5$ & Beech wood & $\bullet \mathrm{CTF}^{* *}=10$ & NA & *Increased & $\begin{array}{c}{ }^{*} \text { Decreased for } \\
\mathrm{NaOH} \leq 0.4 \mathrm{M} \text { and } \\
\text { increased for }>0.4 \\
\mathrm{M}\end{array}$ & "Decreased & $\begin{array}{l}\text { Li et al. } \\
\text { (2014a) }\end{array}$ \\
\hline ZSM-5 & $\begin{array}{l}\text { Desilication by } 0.3 \mathrm{M} \\
\mathrm{NaOH} \text { solution }\end{array}$ & 24.0 & Cellulose & $\bullet \mathrm{CTF}=10$ & NA & ${ }^{*}$ Nearly unchanged & *Increased & $\begin{array}{l}{ }^{*} \text { Nearly } \\
\text { unchanged }\end{array}$ & $\begin{array}{l}\text { Li et al. } \\
(2014 a)\end{array}$ \\
\hline ZSM-5 & $\begin{array}{l}\text { Desilication by } 0.3 \mathrm{M} \\
\mathrm{NaOH} \text { solution }\end{array}$ & 24.0 & Lignin & - $\mathrm{CTF}=10$ & NA & ${ }^{*}$ Increased & *Increased & *Decreased & $\begin{array}{l}\text { Li et al. } \\
(2014 a)\end{array}$ \\
\hline ZSM-5 & $\begin{array}{l}\text { Desilication by } 0.2 \mathrm{M} \\
\mathrm{NaOH} \text { solution }\end{array}$ & 17 & Kraft lignin & $\begin{array}{l}\text { - } \mathrm{T}=600{ }^{\circ} \mathrm{C} \\
-\mathrm{P}=1.013 \mathrm{bar} \\
\cdot \mathrm{RT}=30 \mathrm{~s} \\
\text { - } \mathrm{CTF}=3 \text { and } 5\end{array}$ & ${ }^{*}$ Decreased & ${ }^{*}$ Decreased & NA & NA & $\begin{array}{l}\text { Wang et al. } \\
\text { (2020) }\end{array}$ \\
\hline ZSM-5 & $\begin{array}{l}\text { Hybrid method using } \\
\text { the desilication of ZSM- } \\
5 \text { by } 0.2 \mathrm{M} \mathrm{NaOH} \text { and } \\
\text { the surfactant by CTAB }\end{array}$ & 36 & Kraft lignin & $\begin{array}{c}-\mathrm{T}=600{ }^{\circ} \mathrm{C} \\
-\mathrm{P}=1.013 \mathrm{bar} \\
\cdot \mathrm{RT}=30 \mathrm{~s} \\
\text { - } \mathrm{CTF}=3 \text { and } 5\end{array}$ & "Decreased & $\begin{array}{c}\text { *Increased for } \\
\mathrm{CTF}=3 \text { and } \\
\text { decreased for } \mathrm{CTF}=5\end{array}$ & NA & NA & $\begin{array}{l}\text { Wang et al. } \\
\text { (2020) }\end{array}$ \\
\hline ZSM-5 & $\begin{array}{l}\text { Desilication by } 0.2 \mathrm{M} \\
\mathrm{NaOH} \text { solution }\end{array}$ & 17 & Pyrolytic lignin & $\begin{array}{c}-\mathrm{T}=600{ }^{\circ} \mathrm{C} \\
-\mathrm{P}=1.013 \mathrm{bar} \\
-\mathrm{RT}=30 \mathrm{~s} \\
\text { - } \mathrm{CTF}=3 \text { and } 5\end{array}$ & $\begin{array}{l}{ }^{*} \text { Increased for } \\
\text { CTF }=3 \text { and } \\
\text { decreased for } \\
\text { CTF }=5\end{array}$ & $\begin{array}{l}{ }^{*} \text { Nearly unchanged } \\
\text { for } \mathrm{CTF}=3 \text { and } \\
\text { increased for } \mathrm{CTF}=5\end{array}$ & NA & NA & $\begin{array}{l}\text { Wang et al. } \\
\text { (2020) }\end{array}$ \\
\hline ZSM-5 & $\begin{array}{l}\text { Hybrid method using } \\
\text { the desilication of ZSM- } \\
5 \text { by } 0.2 \mathrm{M} \mathrm{NaOH} \text { and } \\
\text { the surfactant by CTAB }\end{array}$ & 36 & Pyrolytic lignin & $\begin{array}{c}-\mathrm{T}=600{ }^{\circ} \mathrm{C} \\
-\mathrm{P}=1.013 \mathrm{bar} \\
\bullet \mathrm{RT}=30 \mathrm{~s} \\
\text { - } \mathrm{CTF}=3 \text { and } 5\end{array}$ & $\begin{array}{l}{ }^{*} \text { Decreased for } \\
\text { CTF }=3 \text { and } \\
\text { Increased for } \\
\text { CTF }=5\end{array}$ & $\begin{array}{l}\text { *Decreased for } \\
\mathrm{CTF}=3 \text { and increased } \\
\text { for } \mathrm{CTF}=5\end{array}$ & NA & NA & $\begin{array}{l}\text { Wang et al. } \\
\text { (2020) }\end{array}$ \\
\hline HZSM-5 & $\begin{array}{l}\text { Desilication by } 0.2 \mathrm{M} \\
\mathrm{NaOH} \text { solution }\end{array}$ & 45 & Oak & $\begin{array}{c}-\mathrm{T}=500{ }^{\circ} \mathrm{C} \\
-\mathrm{VRT}=1 \mathrm{~s} \\
-\mathrm{CTF}=0.6-8.3\end{array}$ & "Decreased & ${ }^{*}$ Increased & NA & "Increased & $\begin{array}{l}\text { Jia et al. } \\
\text { (2017) }\end{array}$ \\
\hline HZSM-5 & $\begin{array}{l}\text { SAC of the dry gel } \\
\text { performed by dual } \\
\text { templating } \\
\text { (SDA=TPAOH, } \\
\text { surfactant=triblock } \\
\text { copolymer) }\end{array}$ & 49 & Glucose & $\begin{array}{l}\text { - } \mathrm{T}=600{ }^{\circ} \mathrm{C} \\
\text { - } \mathrm{RT}=360 \mathrm{~s} \\
\text { - } \mathrm{CTF}=9.0\end{array}$ & ${ }^{*}$ Increased & ${ }^{*}$ Decreased & NA & ${ }^{*}$ Decreased & $\begin{array}{l}\text { Neumann } \\
\text { and Hicks } \\
(2012 b)\end{array}$ \\
\hline HZSM-5 & $\begin{array}{l}\text { Desilication by } 0.1-0.7 \\
\mathrm{M} \mathrm{NaOH} \text { solutions }\end{array}$ & NA & $\begin{array}{c}\text { Waste } \\
\text { cardboard }\end{array}$ & $\begin{array}{l}\text { - } \mathrm{T}=600{ }^{\circ} \mathrm{C} \\
-\mathrm{RT}=20 \mathrm{~s} \\
\text { - } \mathrm{CTF}=2.0\end{array}$ & "Decreased & ${ }^{*}$ Increased & NA & $\begin{array}{l}{ }^{*} \text { Decreased for } \\
\mathrm{NaOH} \leq 0.5 \mathrm{M} \\
\text { and increased } \\
\text { for }>0.5 \mathrm{M}\end{array}$ & $\begin{array}{l}\text { Ding et al. } \\
\text { (2017) }\end{array}$ \\
\hline HZSM-5 & $\begin{array}{l}\text { Desilication by } 0.2-0.8 \\
\mathrm{M} \mathrm{NaOH} \text { solutions }\end{array}$ & 38 & Cellulose & - $\mathrm{CTF}=20$ & NA & ${ }^{*}$ Decreased & $\begin{array}{c}{ }^{*} \text { Increased for } \\
\mathrm{NaOH} \leq 0.4 \mathrm{M} \text { and } \\
\text { decreased for }>0.4 \\
\mathrm{M}\end{array}$ & ${ }^{*}$ Increased & $\begin{array}{l}\text { Qiao et al. } \\
\text { (2017) }\end{array}$ \\
\hline HZSM-5 & $\begin{array}{l}\text { Desilication by } 0.2-0.8 \\
\mathrm{M} \mathrm{Na}_{2} \mathrm{CO}_{3} \text { solutions }\end{array}$ & 38 & Cellulose & - $\mathrm{CTF}=20$ & NA & ${ }^{*}$ Nearly unchanged & ${ }^{*}$ Decreased & ${ }^{*}$ Decreased & $\begin{array}{l}\text { Qiao et al. } \\
\text { (2017) }\end{array}$ \\
\hline HZSM-5 & $\begin{array}{l}\text { Desilication by } 0.2-0.8 \\
\text { M TPAOH solutions }\end{array}$ & 38 & Cellulose & - $\mathrm{CTF}=20$ & NA & Nearly unchanged & $\begin{array}{l}{ }^{*} \text { Nearly } \\
\text { unchanged }\end{array}$ & $\begin{array}{l}{ }^{*} \text { Nearly } \\
\text { unchanged }\end{array}$ & $\begin{array}{l}\text { Qiao et al. } \\
\text { (2017) }\end{array}$ \\
\hline HZSM-5 & $\begin{array}{l}\text { Integrated desilication } \\
\text { and dealumination by } \\
0.2-1.0 \mathrm{M} \mathrm{NaOH} \text { and } \\
0.1 \mathrm{M} \mathrm{HCl} \text { solutions }\end{array}$ & $15.3-26.1$ & Cellulose & $\begin{array}{l}-\mathrm{T}=550{ }^{\circ} \mathrm{C} \\
-\mathrm{P}=1.013 \mathrm{bar} \\
-\mathrm{CTF}=20\end{array}$ & NA & $\begin{array}{c}\text { *Increased for } \\
\mathrm{NaOH} \leq 0.2 \mathrm{M} \text { and } \\
\text { decreased for }>0.2 \mathrm{M}\end{array}$ & NA & NA & $\begin{array}{l}\text { Hoff et al. } \\
\text { (2017) }\end{array}$ \\
\hline HZSM-5 & $\begin{array}{l}\text { Desilication by } 0.2 \mathrm{M} \\
\mathrm{NaOH} \text { solution while } \\
\text { assisted by } 0-1.0 \\
\text { piperidine }\end{array}$ & $13-20$ & Lignite & $\begin{array}{l}\bullet \mathrm{T}=600{ }^{\circ} \mathrm{C} \\
\cdot \mathrm{P}=1.013 \mathrm{bar} \\
\cdot \mathrm{VRT}=1.5 \mathrm{~s}\end{array}$ & ${ }^{*}$ Decreased & NA & NA & Decreased & $\begin{array}{l}\text { Ren et al. } \\
\text { (2018) }\end{array}$ \\
\hline HZSM-5 & $\begin{array}{l}\text { Desilication by } 0.2-1.0 \\
\mathrm{M} \mathrm{NaOH} \text { solutions }\end{array}$ & NA & Rice straw & $\begin{array}{l}\text { - } \mathrm{T}=600{ }^{\circ} \mathrm{C} \\
-\mathrm{P}=1.013 \mathrm{bar} \\
\text { - } \mathrm{CTF}=20\end{array}$ & NA & ${ }^{*}$ Increased & *Increased & ${ }^{*}$ Decreased & $\begin{array}{l}\text { Chen et al. } \\
\text { (2018a) }\end{array}$ \\
\hline HZSM-5 & $\begin{array}{l}\text { Desilication by } 0.2-1.0 \\
\mathrm{M} \mathrm{NaOH} \text { solutions and } \\
\text { washed with } 0.1 \mathrm{M} \mathrm{HCl} \\
\text { solution }\end{array}$ & NA & Rice straw & $\begin{array}{l}\cdot \mathrm{T}=600{ }^{\circ} \mathrm{C} \\
-\mathrm{P}=1.013 \mathrm{bar} \\
\cdot \mathrm{CTF}=20\end{array}$ & NA & ${ }^{*}$ Increased & *Increased & ${ }^{*}$ Decreased & $\begin{array}{l}\text { Chen et al. } \\
\text { (2018a) }\end{array}$ \\
\hline
\end{tabular}


Table 6.

continued.

\begin{tabular}{|c|c|c|c|c|c|c|c|c|c|}
\hline $\begin{array}{l}\text { Zeolite } \\
\text { framework }\end{array}$ & Synthesis method & $\begin{array}{c}\mathrm{Si} / \mathrm{Al} \text { of } \\
\text { synthesized } \\
\text { zeolite }\end{array}$ & Feedstock (s) & $\begin{array}{l}\text { Operating } \\
\text { conditions }\end{array}$ & $\begin{array}{l}\text { Change in } \\
\text { oxygenates } \\
\text { yield }\end{array}$ & $\begin{array}{l}\text { Change in aromatic } \\
\text { hydrocarbons yield }\end{array}$ & $\begin{array}{c}\text { Change in olefins } \\
\text { yield }\end{array}$ & $\begin{array}{l}\text { Change in coke } \\
\text { formation }\end{array}$ & Reference \\
\hline HZSM-5 & $\begin{array}{l}\text { Desilication by } 0.1-0.9 \\
\mathrm{M} \mathrm{NaOH} \text { solutions }\end{array}$ & NA & Cellulose & $\begin{array}{l}-\mathrm{T}=500{ }^{\circ} \mathrm{C} \\
-\mathrm{P}=1.013 \mathrm{bar} \\
-\mathrm{RT}=30 \mathrm{~s} \\
\text { - } \mathrm{CTF}=20\end{array}$ & $\begin{array}{c}{ }^{*} \text { Nearly } \\
\text { unchanged for } \\
\mathrm{NaOH} \leq 0.5 \mathrm{M} \\
\text { and increased } \\
\text { for }>0.5 \mathrm{M}\end{array}$ & $\begin{array}{c}\text { *Increased for } \\
\mathrm{NaOH} \leq 0.3 \mathrm{M} \text { and } \\
\text { decreased for }>0.3 \mathrm{M}\end{array}$ & NA & $\begin{array}{c}{ }^{*} \text { Decreased for } \\
\mathrm{NaOH} \leq 0.3 \mathrm{M} \\
\text { and increased } \\
\text { for }>0.3 \mathrm{M}\end{array}$ & $\begin{array}{l}\text { Dai et al. } \\
\text { (2018) }\end{array}$ \\
\hline HZSM-5 & $\begin{array}{l}\text { Dual templating by the } \\
\text { SDA of TPAOH and } \\
\text { surfactant of CTAB } \\
\left(\mathrm{CTAB} / \mathrm{SiO}_{2}=0.01-0.05\right)\end{array}$ & NA & Rice straw & $\begin{array}{c}\bullet \mathrm{T}={ }^{\circ} \mathrm{C} \\
-\mathrm{P}=1.013 \mathrm{bar} \\
\cdot \mathrm{CTF}=20\end{array}$ & NA & $\begin{array}{c}{ }^{*} \text { Increased for } \\
\mathrm{CTAB} / \mathrm{SiO}_{2} \leq 0.0 .1 \\
\text { and decreased for } \\
>0.01\end{array}$ & *Increased & $\begin{array}{c}{ }^{*} \text { Decreased for } \\
\mathrm{CTAB} / \mathrm{SiO}_{2} \leq 0.0 \\
.1 \text { and increased } \\
\text { for }>0.01\end{array}$ & $\begin{array}{l}\text { Zhang et al. } \\
\text { (2018a) }\end{array}$ \\
\hline HZSM-5 & $\begin{array}{l}\text { Hard templating by } \\
\text { sucrose with Sucrose/Si } \\
\text { ratios of } 0.15-0.6\end{array}$ & NA & Cellulose & $\begin{array}{l}\text { - } \mathrm{T}=600{ }^{\circ} \mathrm{C} \\
-\mathrm{P}=1.013 \mathrm{bar} \\
\text { - } \mathrm{CTF}=20\end{array}$ & NA & $\begin{array}{c}{ }^{*} \text { Increased for } \\
\text { Sucrose } / \mathrm{SiO}_{2} \leq 0.3 \\
\text { and decreased for } \\
>0.3\end{array}$ & *Increased & $\begin{array}{c}{ }^{*} \text { Decreased for } \\
\text { Sucrose } / \mathrm{SiO}_{2} \leq 0 \text {. } \\
3 \text { and increased } \\
\text { for }>0.3\end{array}$ & $\begin{array}{l}\text { Chen et al. } \\
\text { (2018b) }\end{array}$ \\
\hline HZSM-5 & $\begin{array}{l}\text { Desilication by } 0.3,0.5 \\
\text { M NaOH solutions }\end{array}$ & $17.9-25.5$ & $\begin{array}{l}\text { Lignin (mixed } \\
\text { Guaiacyl/Syrin } \\
\text { gyl type) }\end{array}$ & $\begin{array}{c}-\mathrm{T}=600{ }^{\circ} \mathrm{C} \\
-\mathrm{P}=1.013 \mathrm{bar} \\
-\mathrm{HR}=1000{ }^{\circ} \mathrm{C} / \mathrm{s} \\
\cdot \mathrm{CTF}=1.0\end{array}$ & ${ }^{*}$ Decreased & NA & NA & NA & $\begin{array}{l}\text { Tang et al. } \\
\text { (2019) }\end{array}$ \\
\hline HZSM-5 & $\begin{array}{l}\text { Desilication by } 0.3 \mathrm{M} \\
\mathrm{NaAlO}_{2} \text { solution }\end{array}$ & 17.9 & $\begin{array}{l}\text { Lignin (mixed } \\
\text { Guaiacyl/Syrin } \\
\text { gyl type) }\end{array}$ & $\begin{array}{c}\bullet \mathrm{T}=600^{\circ} \mathrm{C} \\
-\mathrm{P}=1.013 \mathrm{bar} \\
\cdot \mathrm{HR}=1000{ }^{\circ} \mathrm{C} / \mathrm{s} \\
\text { - } \mathrm{CTF}=1.0\end{array}$ & ${ }^{*}$ Decreased & NA & NA & NA & $\begin{array}{l}\text { Tang et al. } \\
\text { (2019) }\end{array}$ \\
\hline HZSM-5 & $\begin{array}{l}\text { Desilication by } 0.3 \mathrm{M} \\
\mathrm{Na}_{2} \mathrm{CO}_{3} \text { solution }\end{array}$ & 30.3 & $\begin{array}{l}\text { Lignin (mixed } \\
\text { Guaiacyl/Syrin } \\
\text { gyl type) }\end{array}$ & $\begin{array}{c}-\mathrm{T}=600{ }^{\circ} \mathrm{C} \\
-\mathrm{P}=1.013 \mathrm{bar} \\
-\mathrm{HR}=1000{ }^{\circ} \mathrm{C} / \mathrm{s} \\
\cdot \mathrm{CTF}=1.0\end{array}$ & ${ }^{*}$ Decreased & NA & NA & NA & $\begin{array}{l}\text { Tang et al. } \\
\text { (2019) }\end{array}$ \\
\hline HZSM-5 & $\begin{array}{l}\text { Desilication by } 0.3 \mathrm{M} \\
\text { TPAOH solution }\end{array}$ & 30.2 & $\begin{array}{l}\text { Lignin (mixed } \\
\text { Guaiacyl/Syrin } \\
\text { gyl type) }\end{array}$ & $\begin{array}{c}\bullet \mathrm{T}=600^{\circ} \mathrm{C} \\
\cdot \mathrm{P}=1.013 \mathrm{bar} \\
\cdot \mathrm{HR}=1000{ }^{\circ} \mathrm{C} / \mathrm{s} \\
\cdot \mathrm{CTF}=1.0\end{array}$ & $\begin{array}{l}\text { *Nearly } \\
\text { unchanged }\end{array}$ & NA & NA & NA & $\begin{array}{l}\text { Tang et al. } \\
\text { (2019) }\end{array}$ \\
\hline HZSM-5 & $\begin{array}{l}\text { Silanization using } \\
\text { PHAPTMS (OTS=5-15 } \\
\text { wt. } \%)\end{array}$ & $37.8-38.2$ & Cellulose & $\begin{array}{l}\text { - } \mathrm{T}=600{ }^{\circ} \mathrm{C} \\
\bullet \mathrm{P}=1.013 \mathrm{bar} \\
\text { - } \mathrm{CTF}=14.3\end{array}$ & NA & "Increased & $\begin{array}{l}\text { *Nearly } \\
\text { unchanged }\end{array}$ & ${ }^{*}$ Decreased & $\begin{array}{l}\text { Qiao et al. } \\
\text { (2019) }\end{array}$ \\
\hline HZSM-5 & $\begin{array}{l}\text { Silanization using } \\
\text { APTMS (OTS=5-15 } \\
\text { wt.\%) }\end{array}$ & $40.3-42.8$ & Cellulose & $\begin{array}{l}-\mathrm{T}=600{ }^{\circ} \mathrm{C} \\
\cdot \mathrm{P}=1.013 \mathrm{bar} \\
\cdot \mathrm{CTF}=14.3\end{array}$ & NA & ${ }^{*}$ Decreased & *Increased & *Increased & $\begin{array}{l}\text { Qiao et al. } \\
\text { (2019) }\end{array}$ \\
\hline $\mathrm{H} \beta$ & $\begin{array}{l}\text { Desilication by } \mathrm{Na}_{2} \mathrm{CO}_{3} \\
\text { solution }\end{array}$ & NA & Lignin & $\begin{array}{l}\bullet \mathrm{T}=500{ }^{\circ} \mathrm{C} \\
\bullet \mathrm{P}=1.013 \mathrm{bar} \\
\bullet \mathrm{CTF}=10\end{array}$ & $*$ Decreased & *Increased & NA & NA & $\begin{array}{l}\text { Bi et al. } \\
\text { (2018) }\end{array}$ \\
\hline $\mathrm{H} \beta$ & $\begin{array}{l}\text { Desilication by } \mathrm{NaOH} \\
\text { solution }\end{array}$ & NA & Lignin & $\begin{array}{l}\bullet \mathrm{T}=500{ }^{\circ} \mathrm{C} \\
\bullet \mathrm{P}=1.013 \mathrm{bar} \\
-\mathrm{CTF}=10\end{array}$ & $*$ Decreased & *Increased & NA & NA & $\begin{array}{l}\text { Bi et al. } \\
\text { (2018) }\end{array}$ \\
\hline $\mathrm{H} \beta$ & $\begin{array}{l}\text { Desilication by } \\
\mathrm{NaOH} / \mathrm{TPAOH} \text { solution }\end{array}$ & NA & Lignin & $\begin{array}{l}-\mathrm{T}=500{ }^{\circ} \mathrm{C} \\
-\mathrm{P}=1.013 \mathrm{bar} \\
\text { - } \mathrm{CTF}=10\end{array}$ & $*$ Decreased & * Increased & NA & NA & $\begin{array}{l}\text { Bi et al. } \\
\text { (2018) }\end{array}$ \\
\hline $\begin{array}{l}\text { HZSM- } \\
\text { 5/MCM-41 }\end{array}$ & $\begin{array}{l}\text { Hybrid method using the } \\
\text { desilication of ZSM- } 5 \\
\text { by } 1.5-3.0 \mathrm{M} \mathrm{NaOH} \text { and } \\
\text { the surfactant by CTAB }\end{array}$ & 27 & Poultry litter & $\begin{array}{l}\bullet \mathrm{T}=500{ }^{\circ} \mathrm{C} \\
\bullet \mathrm{P}=1.013 \mathrm{bar}\end{array}$ & $\begin{array}{l}\text { *Decreased for } \\
\mathrm{NaOH} \leq 2.5 \mathrm{M} \\
\text { and increased } \\
\text { for }>2.5 \mathrm{M}\end{array}$ & $\begin{array}{c}\text { *Increased for } \\
\mathrm{NaOH} \leq 2.0 \mathrm{M} \text { and } \\
\text { decreased for }>2.0 \mathrm{M}\end{array}$ & NA & 'Decreased & $\begin{array}{l}\text { Zhang et al. } \\
\text { (2018a) }\end{array}$ \\
\hline $\begin{array}{l}\text { HZSM- } \\
\text { 5/MCM-41 }\end{array}$ & $\begin{array}{l}\text { Hybrid method using the } \\
\text { desilication of } \mathrm{ZSM}-5 \\
\text { by } 2.0 \mathrm{M} \mathrm{NaOH} \text { and the } \\
\text { surfactant by CTAB }\end{array}$ & 27 & $\begin{array}{l}\text { Co-feed } \\
\text { distillers dried } \\
\text { grains with } \\
\text { solubles (D) } \\
\text { and waste } \\
\text { agricultural } \\
\text { plastic } \\
\text { mulching films } \\
\text { (W) }\end{array}$ & $\begin{array}{l}\bullet \mathrm{T}=650{ }^{\circ} \mathrm{C} \\
\bullet \mathrm{P}=1.013 \mathrm{bar} \\
\cdot \mathrm{W} / \mathrm{D}=1.0\end{array}$ & NA & *Increased & *Increased & "Decreased & $\begin{array}{l}\text { Zhang et al. } \\
\text { (2018b) }\end{array}$ \\
\hline $\begin{array}{l}\text { HZSM- } \\
\text { 5/MCM-41 }\end{array}$ & $\begin{array}{l}\text { Hybrid method using the } \\
\text { desilication of ZSM- } 5 \\
\text { by } 2.0 \mathrm{M} \mathrm{NaOH} \text { and the } \\
\text { surfactant by CTAB }\end{array}$ & 27 & $\begin{array}{l}\text { Co-feed Waste } \\
\text { greenhouse } \\
\text { plastic films } \\
\left(\mathrm{F}_{1}\right) \text { and rice } \\
\text { husk }\left(\mathrm{F}_{2}\right)\end{array}$ & $\begin{array}{c}-\mathrm{T}=600{ }^{\circ} \mathrm{C} \\
-\mathrm{P}=1.013 \text { bar } \\
\text { - } \mathrm{CTF}=2 \\
\text { - } \mathrm{F}_{1} / \mathrm{F}_{2}=1.5\end{array}$ & ${ }^{*}$ Decreased & *Increased & NA & NA & $\begin{array}{l}\text { Li et al. } \\
(2020)\end{array}$ \\
\hline
\end{tabular}

* Change in yield compared to parent microporous zeolite.

** Abbreviations: APTMS: (3-aminopropyl)trimethoxysilane; CFT: Catalyst-to-feed ratio; CTAB: hexadecyltrimethylammonium bromide; HR: Heating rate; NA: Not available; OTS:

Organosilane-to-silica ratio; P: Pressure; PHAPTMS: 3-(Phenylamino)propyltrimethoxysilane; RT: Residence time; SAC: Steam assisted crystallization; SDA: Structure-directing agent;

T: Temperature; TPAOH: Tetrapropylammonium hydroxide; VRT: Vapor residence time. 


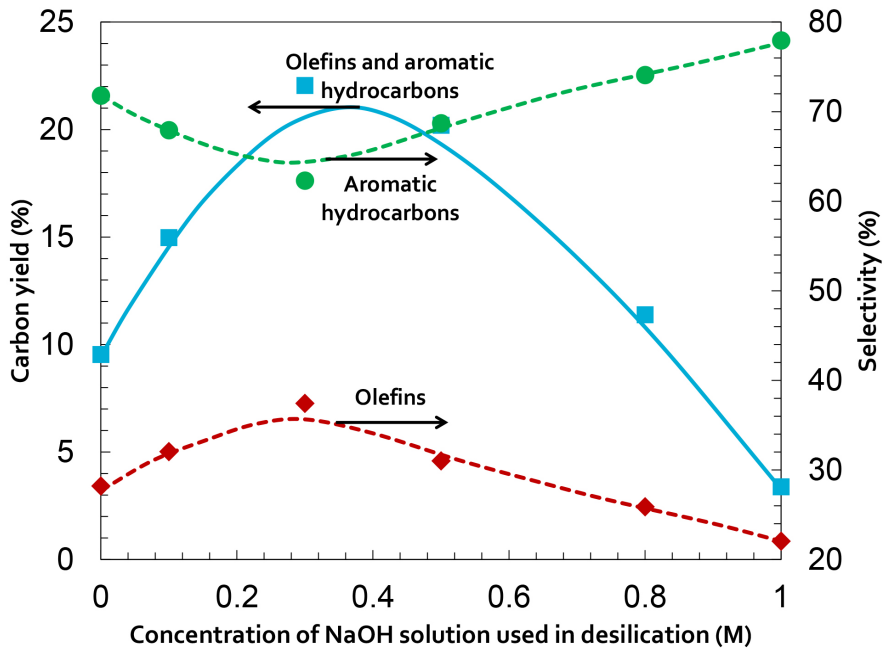

Fig. 6. The production of olefins and aromatic hydrocarbons over hierarchical HZSM-5 zeolites treated by different $\mathrm{NaOH}$ solutions. Redrawn with permission from Shao et al. (2016). Copyright $\odot 2016$ Royal Society of Chemistry (License ID: 1058135-1).

$\mathrm{M} \mathrm{NaOH}$ (Fig. 6). They showed that the HZSM-5 zeolite treated by $0.3 \mathrm{M}$ $\mathrm{NaOH}$ improved the resistance to deactivation associated with coke deposition, although it produced higher coke by $11.6 \%$.

It is of paramount importance that different types of alkali solutions used for the desilication process could also impose distinct morphologies on zeolites, varying the product distribution and selectivity of the CFP process. Qiao et al. (2017) conducted the CFP of cellulose to produce aromatics over the mesoporous hierarchical ZSM-5 zeolites desilicated using various alkali solutions of $\mathrm{NaOH}, \mathrm{Na}_{2} \mathrm{CO}_{3}$, and tetrapropylammonium hydroxide (TPAOH) with different concentrations under fixed treatment conditions. They found that the desilication process with $\mathrm{Na}_{2} \mathrm{CO}_{3}$ solution was more controllable than that with $\mathrm{NaOH}$ solution. Thus, the former synthesized the micro/mesoporous hierarchical catalysts with higher acid sites. In terms of product selectivity, the CFP over $\mathrm{Na}_{2} \mathrm{CO}_{3}$-treated catalyst increased the aromatic production, while the $\mathrm{NaOH}$-treated counterpart tended to decrease the amount of aromatics. The amount of coke formation followed opposite trends. Due to the increased acidity of the $\mathrm{Na}_{2} \mathrm{CO}_{3}$-treated ZSM-5 zeolites, they had a high tendency to

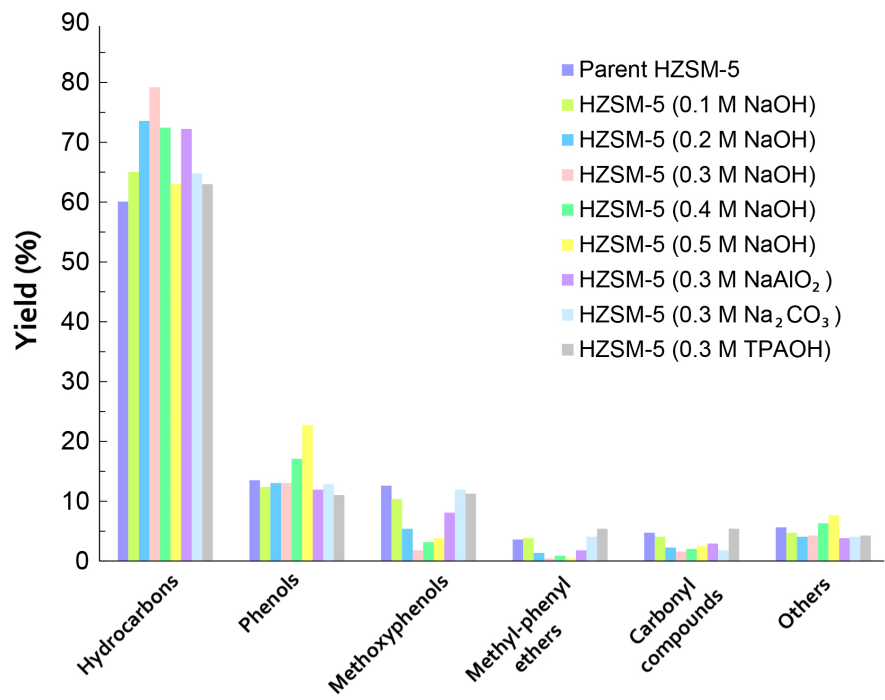

Fig. 7. The impact of the different types of hierarchical HZSM-5 zeolites (treated with different desilication processes) on the relative selectivity of different products produced in the CFP process. Adapted from Tang et al. (2019). valuable mono-aromatics (i.e., benzene, toluene, and xylene) rather than large poly-aromatics. Interestingly, the TPAOH did not have a considerable impact on the parent ZSM-5 pore structure, whereas it substantially improved the relative crystallinity. It was noticed that the TPAOH treatment had a repairing ability during the desilication process of HZSM5 zeolite, slightly improving the aromatic formation in the CFP process.

Tang et al. (2019) evaluated the CFP of lignin over different hierarchical HZSM-5 zeolites prepared by desilication treatment of commercial HZSM 5 zeolite using (a) 0.1-0.5 M NaOH solutions, (b) $0.3 \mathrm{M} \mathrm{NaAlO}_{2}$, (c) $0.3 \mathrm{M}$ $\mathrm{Na}_{2} \mathrm{CO}_{3}$, and (d) $0.3 \mathrm{M}$ TPAOH. They pointed out that the HZSM-5 zeolite desilicated by $0.3 \mathrm{M} \mathrm{NaOH}$ had the best performance in cracking the bulky oxygenates released from lignin to produce aromatic hydrocarbons (Fig. 7)

It should be mentioned that the rate of desilication by $\mathrm{NaOH}$ solution alone is fairly fast, leading to the formation of mesopores in an uncontrollable manner, losing a considerable amount of acid sites. The introduction of protecting agents, such as TPAOH, tetrabutylammonium hydroxide (TBAOH), and piperidine could be advantageous in alleviating the desilication severity of $\mathrm{NaOH}$ solution. Ren et al. (2018) evidenced that the presence of piperidine solutions with concentrations $<0.3 \mathrm{M}$ could prevent the $0.2 \mathrm{M} \mathrm{NaOH}$ solution from deep destruction of the HZSM-5 structure. In terms of zeolite acidity, the hierarchical HZSM-5 structure prepared by $0.2 \mathrm{M} \mathrm{NaOH}+0.1 \mathrm{M}$ piperidine had a higher amount of acid sites (i.e., $0.88 \mathrm{mmol} / \mathrm{g}$ ) compared with its non-desilicated counterpart $(0.75$ $\mathrm{mmol} / \mathrm{g}$ ). Mechanistically, owing to its hydrophobicity, piperidine tends to interact with the hydrophobic $\mathrm{Si}-\mathrm{OH}$ terminals through electrostatic connections and subsequently stops more desilication of the zeolite structure (Fig. 8) (Wang et al., 2017). However, it has been pointed out that excessive concentrations of piperidine could exert adverse effects by attacking the lattice $\mathrm{Al}$ atoms during the extraction of the $\mathrm{Si}$ atoms by the alkaline solution. Overall, desilication assisted by $0.3 \mathrm{M}$ piperidine has been found ideal because of attaining the highest selectivity towards light aromatics (i.e., benzene, toluene, ethylbenzene, xylene, and naphthalene) (Ren et al., 2018).

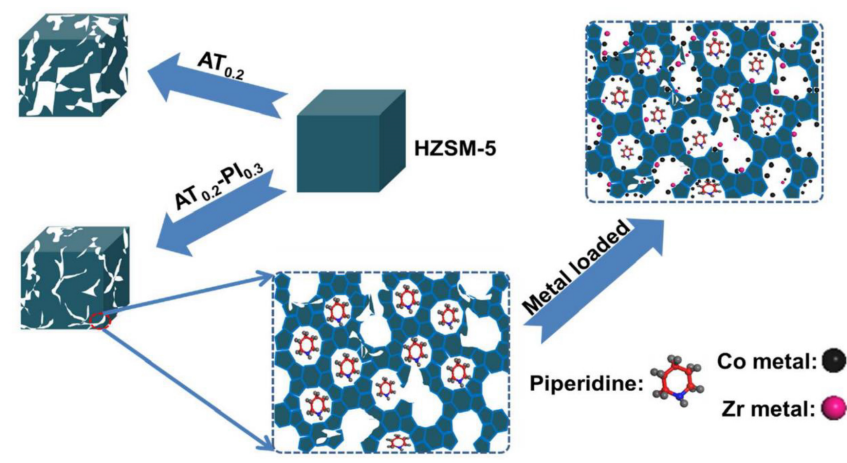

Fig. 8. The schematic view of desilication process of zeolites assisted by piperidine as well as its modification by bi-metals. Reprinted with permission from Ren et al. (2018). Copyright@ 2018 American Chemical Society.

It is worth mentioning that the time of desilication treatment could considerably affect the morphology of hierarchical zeolites and subsequently change product selectivity of the CFP process. Wang et al (2017) indicated that alkali treatment times longer than $4 \mathrm{~h}$ damaged the crystallinity of HZSM-5 zeolite. Furthermore, an increase in desilication time decreased the number of active acid sites. From the product selectivity point of view, the modest time of $4 \mathrm{~h}$ improved aromatic yields.

Another fundamental factor is the $\mathrm{Si} / \mathrm{Al}$ atomic ratio of the parent zeolite which could substantially impact the desilicated mesoporosity. It has been shown that the desilication treatment of the ZSM-5 generated optimal mesopores with the highest surface areas for $\mathrm{Si} / \mathrm{Al}$ atomic ratios within the range of 25-50 (Groen et al., 2004). For lower ratios, the high amount of aluminum prevents the removal of silica from the framework, generating a relatively low mesoporosity in ZSM-5 (Groen et al., 2006). For higher ratios, excessive silica is dissolved, resulting in the generation of larger 
pores of lower mesopore surface areas (Serrano and Pizarro, 2013). Kim et al. (2012) reported that through $\mathrm{Na}_{2} \mathrm{CO}_{3}$-assisted desilication, the parent ZSM-5 zeolites with $\mathrm{Si} / \mathrm{Al}$ ratio of 42 could establish a bimodal mesoporous zeolitic system (intraparticle mesoporosity, i.e., cylinders and cavities). The cylindrical mesopores connected internal micropores to external surface of the catalyst. This structure showed an increase in the stability of the catalyst during the conversion of olefins (i.e., 2-methyl-2-butene) to aromatic hydrocarbons (Kim et al., 2012).

\subsection{Dual templating using surfactants}

Dual templating strategy is applied to prepare ordered mesoporous zeolites. This strategy integrates a structure-directing agent synthesizing the main structure of the zeolite and a surfactant forming the mesoporous phase. The surfactant breeds the micelles acting as template for the mesoporous structure while the structure-directing agent forms the crystal phase around the walls of mesoporous configuration (Serrano and Pizarro, 2013). Zhang et al. (2018a) prepared hierarchical HZSM-5 zeolites through the dual templating method in which TPAOH was employed as the structure-directing agent and hexadecyltrimethylammonium bromide (CTAB) was used as the mesopore template with the $\mathrm{CTAB} / \mathrm{SiO}_{2}$ ratios of $0.01-0.05$. It was revealed that the incorporation of the $\mathrm{CTAB}$ template did not ruin the crystallinity of the microporous HZSM-5. Moreover, as the $\mathrm{CTAB} / \mathrm{SiO}_{2}$ ratio increased in the synthesis process, the mesopore surface area and volume steadily increased at the expense of micropore surface and volume. On the contrary, the total acidity of the catalyst peaked at the lowest $\mathrm{CTAB} / \mathrm{SiO}_{2}$ ratio of 0.01 . Therefore, the hierarchical zeolite associated with this $\mathrm{CTAB} / \mathrm{SiO}_{2}$ ratio attained the maximum aromatic yield (i.e., 26.8\%) and the minimum coke formation (39.2\%) (Fig. 9). Unlike aromatics, the optimal $\mathrm{CTAB} / \mathrm{SiO}_{2}$ ratio for the production of olefins was 0.03 .

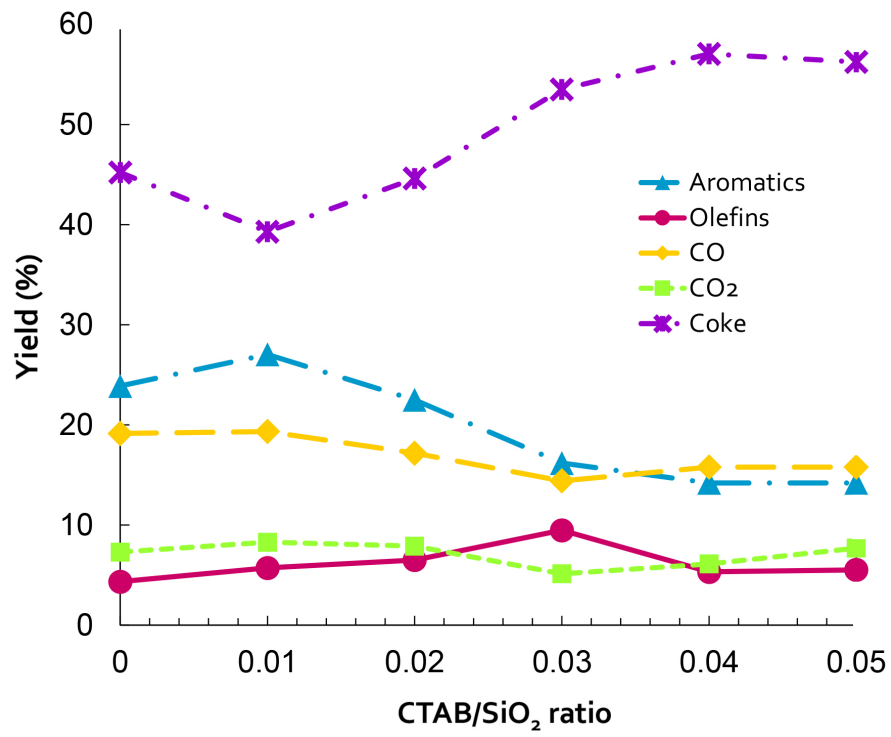

Fig. 9. Effect of $\mathrm{CTAB} / \mathrm{SiO}_{2}$ ratio used for synthesizing hierarchical HZSM-5 zeolites on product distribution of the CFP of rice straw. Adapted from Zhang et al. (2018a).

\subsection{Hard templating}

In the hard templating strategy, solids with certain porosity are used as template to confine aluminosilicate species among their pore spaces in order to form mesoporous zeolites after the removal of the template (Fig. 10). This technique can facilitate the formation of ordered mesoporous structure and offers a precise control over the size of mesopores (Chen et al., 2011). Basically, the desired configuration of hard template can lead to the formation of mesoporosity with the anticipated structure. However, the hard templating method requires complex multiple steps due to the possible mismatches between the aluminosilicate species and the hard template (Zhou et al., 2011).

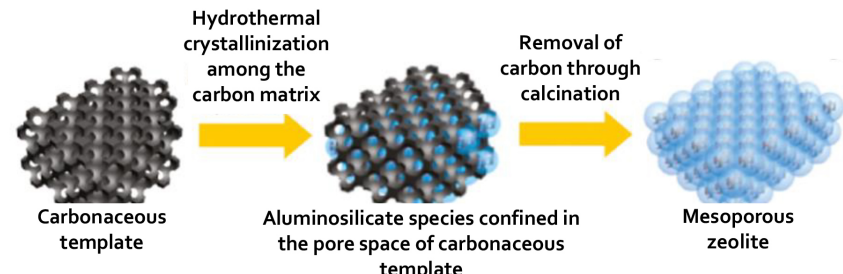

template

Fig. 10. A Schematic presentation of synthesizing hierarchical zeolites using the hard templating technique (by carbonaceous template). Reprinted and modified with permission from Chen et al. (2011). Copyright@ 2011 American Chemical Society.

Moreover, the destruction of the hard template for achieving the hierarchical mesoporosity needs severe conditions which could be harmful to the zeolite microporosity (Serrano and Pizarro, 2013).

There is a broad range of hierarchical zeolites synthesized by different types of carbonaceous materials such as glucose and sucrose (Serrano and Pizarro, 2013). Chen et al. (2018b) used the hard templating method utilizing sucrose (with sucrose/ $\mathrm{SiO}_{2}$ ratios of $0.15-0.6$ ) as the mesotemplate to prepare hierarchical HZSM-5 zeolites. Increased addition of sucrose led to an increase in both mesopore surface area and volume at the expense of a decrease in the micropore surface area and volume. The authors observed that the CFP of cellulose over the hierarchical catalyst prepared from sucrose (sucrose $/ \mathrm{SiO}_{2}$ ratio of 0.15 ) yielded the maximum amount of aromatics (i.e., 37.0\%) and the minimum coke (i.e., 30.4\%) (Fig. 11). However, the highest olefin yield was attained over the hierarchical zeolites fabricated by hard templating using sucrose and with a sucrose $/ \mathrm{SiO}_{2}$ of 0.6

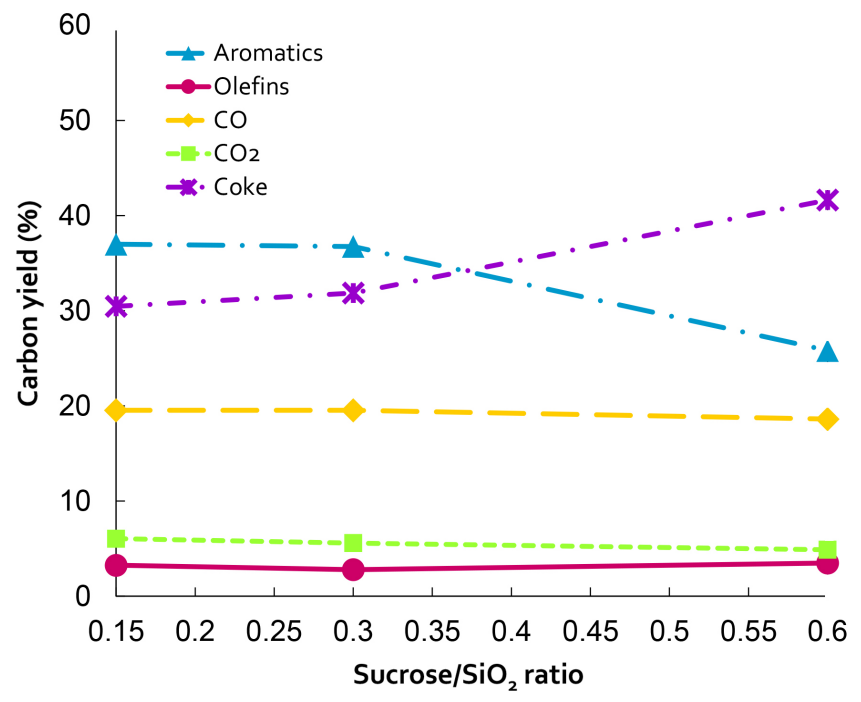

Fig. 11. Effect of sucrose/ $/ \mathrm{SiO}_{2}$ ratio used for synthesizing hierarchical HZSM-5 zeolites (via hard templating method) on product distribution during the CFP of cellulose. Adapted from Chen et al. (2018b).

\subsection{Zeolitization of raw solid gel}

Unlike the conventional hydrothermal routes, the main concept of zeolitization technique is based on the crystallization of a prepared aluminosilicate dry-gel using vapors. This strategy can be generally classified into two procedures of vapor phase transport (VPT) and steamassisted conversion (SAC). In the former, the prepared dry gel is crystallized by a vapor consisting of water and structure-directing agents. In the latter, water vapor alone is involved in the crystallization of the dry gel and the structure-directing agents are contained in the solid phase (Li et al., 2014a). Jia et al. (2018) proved that the hierarchical ZSM-5 zeolite 
made by the SAC method showed more favorable catalytic lifetime and selectivity toward mono-aromatic hydrocarbons in methanol aromatization reaction compared with its mesoporous counterpart prepared by the conventional hydrothermal procedure.

Zang et al. (2018) applied the SAC method to synthesize the hierarchical HZSM-5 zeolites with low Si/Al ratios $(<30)$. In preparing the solid gel, they tested different templates including sucrose, polyethylene glycol, and Pluronic P123 along with TPAOH as the structure-directing agent. Among them, sucrose was found as a suitable option for creating the hierarchical HZSM-5 zeolites with meso/macroprosity. Neumann and Hicks (2012a) conducted the CFP of glucose over the hierarchical HZSM-5 zeolites synthesized by the SAC process. The dry gel of this catalyst was prepared by the dual templating method using a solution of triblock copolymer (as the surfactant) and TPAOH (as the structure-directing agent). Compared to the parent HZSM-5 zeolite, the hierarchical catalyst led to an increase in the oxygenate yield and a decrease in the aromatic production.

\subsection{Silanization}

In the silanization technique, some kinds of organosilanes are utilized to produce a secondary mesoporosity in zeolites. These materials have a propensity to interact with the aluminosilicate and silicate fractions of the solid phase gel, and are anchored by silanol functional groups to form various organofunctionalized silica configurations. In this regard, the organosilane fractions do not allow the gel to be crystallized in the normal way conventional zeolites are. As a consequence, the crystallization process develops organicinorganic complexes which are further destroyed through calcination to generate hierarchical pores inside zeolites (Serrano and Pizarro, 2013). Zhang et al. (2018b) used various organosilanes with different chain lengths and ionic compositions including methyltrimethoxysilane (MTMS), propyltrimethoxysilane (PTMS), octyltrimethoxysilane (OTMS), hexadecyltrimethoxysilane (HTMS), and dimethylhexadecyl[3(trimethoxysilyl)propyl]ammonium chloride (TPHAC) to prepare hierarchical HZSM-5 zeolites. They observed that the HTMS was the optimal organosilane for generating the hierarchical zeolites for the CFP process of rice straw as it produced the highest yield of aromatics (about 25.5\%) and the lowest amount of coke (about $43.3 \%$ ) (Fig. 12).

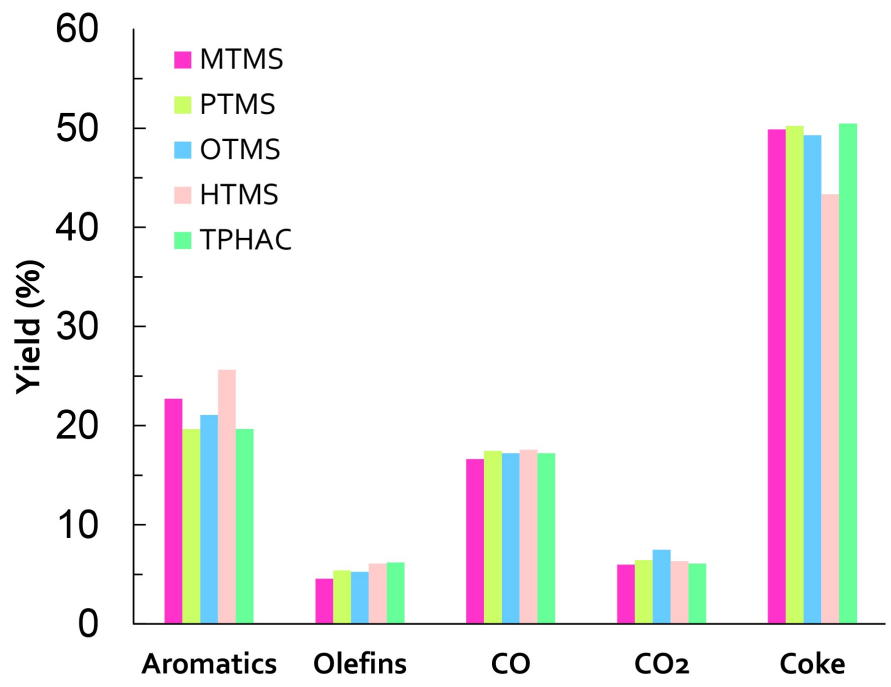

Fig. 12. Effects of different organosilanes used for synthesizing hierarchical HZSM-5 zeolites on product distribution of the CFP of rice straw. Redrawn with permission from Zhang et al. (2018b). Copyright@ 2018 American Chemical Society.

In addition, it was discovered that the presence of ammonium ion inside organosilanes hindered the formation of aromatics and increased the coke deposition, while it augmented olefin production. Qiao et al. (2019) investigated the CFP of cellulose over two series of hierarchical ZSM-5 zeolites synthesized using two different organosilanes 3(phenylamino)propyltrimethoxysilane (PHAPTMS) and (3aminopropyl)trimethoxysilane (APTMS) as the mesopore-directing agents $\mathrm{NH}_{3}$-TPD analysis exhibited that the strength and amounts of the acid sites in the hierarchical HZSM-5 zeolites were nearly unchanged as the organosilane/silica ratios were varied. This study reported that the maximum aromatic yield of 41.8 was achieved for the CFP over the hierarchical ZSM-5 catalyst synthesized by PHAPTMS with the organosilane/silica ratio of $10 \mathrm{wt} \%$.

\subsection{Hybrid}

Hybrid methods refer to the combination of different approaches to achieve a favorable control over producing hierarchical micromesoporosity. One of the hybrid strategies applied for the formation of hierarchical zeolites is the post-synthesis treatment using both alkaline solution and surfactants. In this case, the dissolution of silica happens locally and the surfactant micelles rearrange the zeolitic units to form the mesoporosity. Zhang et al. (2018a) utilized 1.5-3.0 M NaOH for the desilication and CTAB as surfactant to synthesize the hierarchical ZSM5/MCM-41 catalyst. In this catalyst, the MCM-41 moiety was formed as an external shell layer stuck onto the ZSM-5 moiety at the core. The authors evaluated this catalyst in the microwave-assisted CFP of poultry litter. They observed that the lowest bio-oil was produced by using the catalys prepared with the $\mathrm{NaOH}$ concentration of $2 \mathrm{M}$. However, the highest quantity of aromatic hydrocarbons was also generated using the same catalyst overshadowing its low bio-oil yield (Fig. 13). In addition to the concentration of $\mathrm{NaOH}$ solution, Li et al. (2019) argued that the mass fraction of the surfactant used for preparing the hierarchical HZSM5/MCM-41 zeolite was also instrumental. They reported that $10 \mathrm{wt} \%$ of $\mathrm{CTAB}$ led to the production of the highest amounts of aromatic hydrocarbons and olefins during the CFP of rice husk (totally 54\%) (Fig. 14).

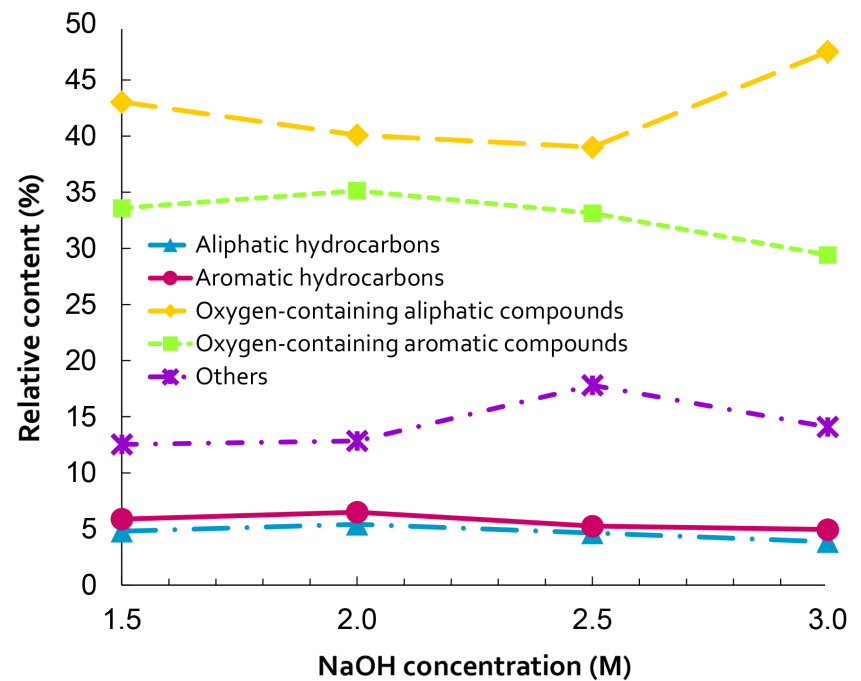

Fig. 13. Effect of $\mathrm{NaOH}$ concentration used for synthesizing the hierarchical ZSM-5/MCM41 catalyst on the chemical compositions of bio-oil. Adapted from Zhang et al. (2018a).

Using a hierarchical HZSM-5/MCM-41 catalyst, Li et al. (2020) assessed the synergetic effects between two feedstocks (rice husk and waste greenhouse plastic films) in the CFP. They showed that the maximum hydrocarbon yield of $71.1 \%$ was achieved at $600{ }^{\circ} \mathrm{C}$ using the mass ratio of rice husk to waste greenhouse plastic films of $1: 1.5$. In a microwaveassisted co-pyrolysis over the hierarchical HZSM-5/MCM-41 zeolite, Zhang et al. (2018b) used distillers dried grains with solubles (D) and waste agricultural plastic mulching films (W) as feedstocks and $\mathrm{SiC}$ as microwave absorbent. They revealed that the integrated hierarchical catalyst and 


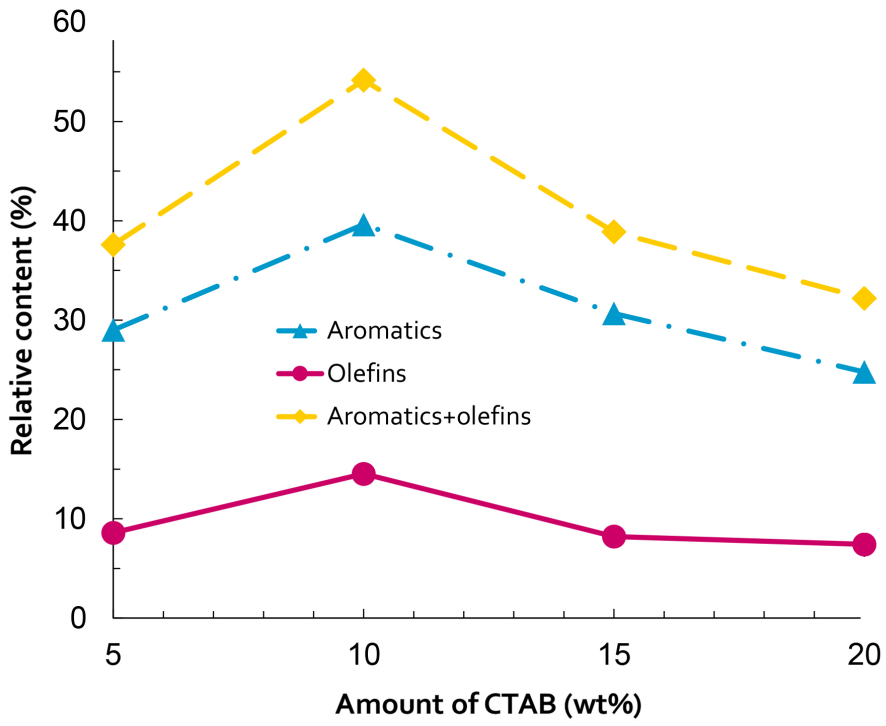

Fig. 14. Effect of the mass fraction of the surfactant (CTAB) used for synthesizing the hierarchical ZSM-5/MCM-41 catalyst on the chemical compositions of the generated bio-oil. Adapted from Li et al. (2019).

microwave absorbent increased the yields of aromatics and olefins remarkably. Their findings showed that the optimal temperature of the microwave-assisted catalytic fast co-pyrolysis for the production of aromatics was around $650{ }^{\circ} \mathrm{C}$. Moreover, the mass ratio (W/D) of 1.0 was found to be the best mixture to yield the highest hydrocarbons.

\section{Effects of metal-loaded hierarchical zeolites in catalytic pyrolysis}

Due to the presence of secondary mesoporosity in the hierarchical zeolites, they can be used in the preparation of catalysts with higher dispersion of additional active phases (e.g., metal nanoparticles), compared with their microporous counterparts in which active sites are only localized on the external surface (Serrano and Pizarro, 2013). Moreover, the application of hierarchical zeolites as catalyst framework could reduce the propensity for sintering and forming large metal nanoparticles (Puértolas et al., 2014). However, the loading of metals into hierarchical zeolites could decrease the number of Brønsted acid sites and increase the amount of Lewis acid sites (Table 7). This could be ascribed to the incorporation of metal cations into the ion-exchange positions during impregnation. In addition, the surface area is slightly reduced since the zeolite pores might be blocked by metal species (Table 7). Table 8 presents the changes in yields of the main products of biobased CFP process (i.e., oxygenates, aromatics, olefins, and coke) over different metallic hierarchical zeolites (prepared by different synthesis methods) in comparison with their microporous and nonmetallic hierarchical counterparts.

\subsection{Nickel loading}

The presence of Ni metal on hierarchical zeolites, such as bimodal micromesoporous $\beta$ zeolite, leads to a high selectivity toward producing gasoline- range products. Moreover, it could promote olefin conversion through olefin aromatization and hydroisomerization reactions (Escola et al., 2012). However, the extent of olefin conversion considerably depends on the type of hierarchical zeolite. It has been observed that olefins were completely converted through the hydrogenation reaction over the hierarchical Ni/ $\beta$ zeolite, whereas around $30 \%$ of the olefins remained unconverted by using the hierarchical Ni/ZSM-5 because of an insufficient balance between the acid and metal functions (Escola et al., 2011).

It should be noted that the incorporation of metallic species significantly reduces the Brønsted acidity of hierarchical zeolites. In this regard, Veses et al. (2016) showed that the decreased amount of Brønsted acidity in the hierarchical ZSM-5 zeolites loaded by different metals (i.e., $\mathrm{Ni}, \mathrm{Sn}, \mathrm{Cu}$, and $\mathrm{Mg}$ ) led to lower production of aromatic hydrocarbons. On the contrary, Dai et al. (2019) achieved different results during the CFP of torrefied corn cob over a Ni-modified hierarchical ZSM-5 catalyst and recorded improved yields of aromatic hydrocarbons.

\subsection{Iron loading}

Dai et al. (2018) observed that the addition of Fe to hierarchical HSM-5 had an inverse impact on aromatic yields during the CFP of cellulose. Furthermore, $\mathrm{Fe}$ modification tended to produce mono-aromatics, especially BTX compounds, while reducing the poly-aromatics.

\subsection{Copper loading}

Chen et al. (2018a) compared the yields of aromatics produced from the CFP of rice straw over the hierarchical HZSM-5 zeolites modified by different metals (i.e., $\mathrm{Ni}, \mathrm{Cu}, \mathrm{Zn}$, and $\mathrm{Ga}$ ). They observed that the $\mathrm{Cu}$ incorporated hierarchical zeolite showed the highest performance in the production of aromatics (Fig. 15). Based on their finding, the incorporation of $\mathrm{Zn}$ and $\mathrm{Ga}$ affected the formation of aromatics insignificantly. It was also

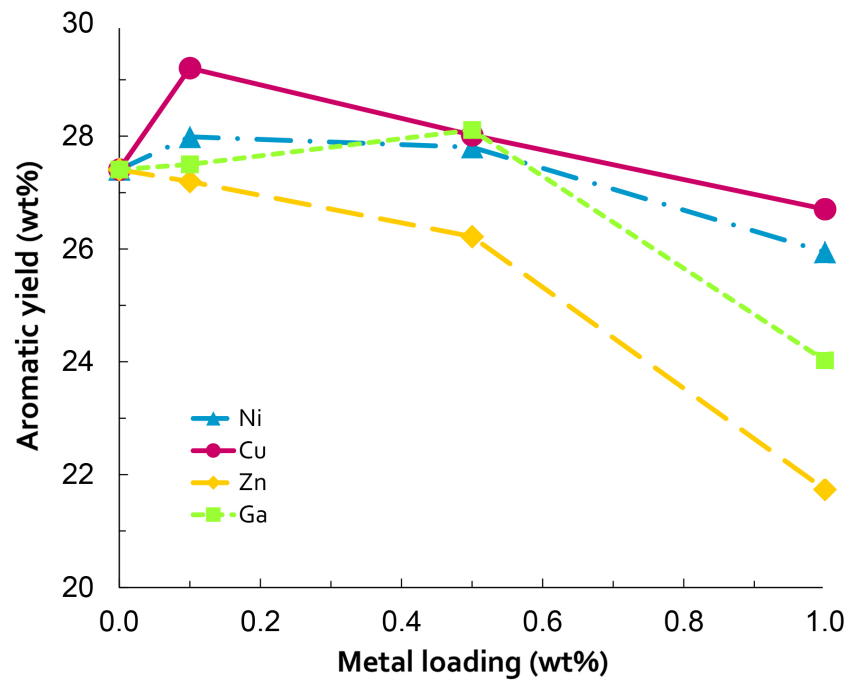

Fig. 15. Aromatic yields produced from the CFP of rice straw over the $0.2 \mathrm{M}-\mathrm{NaOH}$ desilicated hierarchical HZSM-5 zeolites modified with different metals and at various metal loadings. Adapted from Chen et al. (2018a).

Table 7.

Porous and acidic features of nonmetalic and metal-loaded hierarchical zeolites*.

\begin{tabular}{|c|c|c|c|c|c|c|c|}
\hline \multicolumn{3}{|c|}{ Catalyst } & \multicolumn{3}{|c|}{ Porous characteristics } & \multicolumn{2}{|c|}{ Acid properties } \\
\hline Mesoporous zeolite & Loaded metal & $\mathbf{S i} / \mathbf{A l}$ & $\mathrm{S}_{\mathrm{BET}}\left(\mathrm{m}^{2} / \mathrm{g}\right)$ & $\mathrm{V}_{\text {MICRO }}\left(\mathrm{cm}^{3} / \mathrm{g}\right)$ & $\mathrm{V}_{\mathrm{MESO}}\left(\mathrm{cm}^{3} / \mathrm{g}\right)$ & $\mathrm{C}_{\mathrm{B}, 200}(\mu \mathrm{mol} / \mathrm{g})$ & $\mathrm{C}_{\mathrm{L}, 200}(\mu \mathrm{mol} / \mathrm{g})$ \\
\hline HZSM-5 & - & 40 & 528 & 0.12 & 0.51 & 233 & 28 \\
\hline HZSM-5 & Sn & 40 & 518 & 0.13 & 0.53 & 163 & 64 \\
\hline HZSM-5 & $\mathrm{Cu}$ & 40 & 471 & 0.13 & 0.41 & 108 & 166 \\
\hline HZSM-5 & $\mathrm{Ni}$ & 40 & 500 & 0.13 & 0.54 & 148 & 270 \\
\hline HZSM-5 & $\mathrm{Mg}$ & 40 & 456 & 0.13 & 0.33 & 75 & 144 \\
\hline
\end{tabular}

* Source: Reproduced with permission from Veses et al. (2016). Copyright@ 2016 American Chemical Society. 
Table 8 .

The changes in yields of the main products of bio-based CFP process over different metallic hierarchical zeolites prepared by different synthesis methods.

\begin{tabular}{|c|c|c|c|c|c|c|c|c|c|c|}
\hline $\begin{array}{l}\text { Metal(s) (wt\%) } \\
\text { [Loading } \\
\text { method] }\end{array}$ & $\begin{array}{l}\text { Zeolite } \\
\text { framework }\end{array}$ & Synthesis method & $\begin{array}{c}\mathrm{Si} / \mathrm{Al} \text { of } \\
\text { synthesized } \\
\text { zeolite }\end{array}$ & Feedstock (s) & $\begin{array}{l}\text { Operating } \\
\text { conditions }\end{array}$ & $\begin{array}{c}\text { Change in } \\
\text { oxygenates } \\
\text { yield }\end{array}$ & $\begin{array}{c}\text { Change in } \\
\text { aromatic } \\
\text { hydrocarbons } \\
\text { yield }\end{array}$ & $\begin{array}{l}\text { Change in } \\
\text { olefins yield }\end{array}$ & $\begin{array}{c}\text { Change in } \\
\text { coke } \\
\text { formation }\end{array}$ & Reference \\
\hline $\begin{array}{l}\operatorname{Mg}(1.0) \\
{[\mathrm{WI}]}\end{array}$ & HZSM-5 & $\begin{array}{l}\text { Desilication by } \\
0.2 \mathrm{M} \mathrm{NaOH} \\
\text { solution }\end{array}$ & 40 & $\begin{array}{c}\text { Bio-oil from } \\
\text { woody } \\
\text { biomass }\end{array}$ & $\begin{array}{c}-\mathrm{T}=450{ }^{\circ} \mathrm{C} \\
-\mathrm{P}=1.013 \mathrm{bar}\end{array}$ & ${ }^{* *}$ Decreased & ${ }^{* *}$ Decreased & NA & ${ }^{* *}$ Decreased & $\begin{array}{l}\text { Veses et al. } \\
\text { (2016) }\end{array}$ \\
\hline $\begin{array}{l}\operatorname{Mg}(8.4) \\
{[W I]}\end{array}$ & HZSM-5 & $\begin{array}{l}\text { Silanization using } \\
\text { PHAPTMS } * * *\end{array}$ & 58 & $\begin{array}{l}\text { Eucalyptus } \\
\text { woodchips }\end{array}$ & $\begin{array}{l}-\mathrm{T}=500{ }^{\circ} \mathrm{C} \\
-\mathrm{P}=1.013 \mathrm{bar} \\
-\mathrm{CTF}=0.2\end{array}$ & ${ }^{* *}$ Decreased & NA & NA & ${ }^{* *}$ Decreased & $\begin{array}{l}\text { Hernando } \\
\text { et al. (2017) }\end{array}$ \\
\hline $\begin{array}{l}\operatorname{Mg}(8.7) \\
{[W I]}\end{array}$ & $\mathrm{H} \beta$ & $\begin{array}{l}\text { Silanization using } \\
\text { PHAPTMS }\end{array}$ & 24 & $\begin{array}{l}\text { Eucalyptus } \\
\text { woodchips }\end{array}$ & $\begin{array}{l}\bullet \mathrm{T}=500{ }^{\circ} \mathrm{C} \\
-\mathrm{P}=1.013 \text { bar } \\
\text { - } \mathrm{CTF}=0.2\end{array}$ & ${ }^{* *}$ Decreased & NA & NA & ${ }^{* *}$ Decreased & $\begin{array}{l}\text { Hernando } \\
\text { et al. (2017) }\end{array}$ \\
\hline $\begin{array}{l}\mathrm{Fe}(1.0) \\
{[\mathrm{WI}]}\end{array}$ & HZSM-5 & $\begin{array}{l}\text { Desilication by } \\
0.3 \mathrm{M} \mathrm{NaOH} \\
\text { solution }\end{array}$ & NA & Cellulose & $\begin{array}{c}\text { - } \mathrm{T}=500{ }^{\circ} \mathrm{C} \\
-\mathrm{P}=1.013 \mathrm{bar} \\
-\mathrm{RT}=30 \mathrm{~s} \\
\text { - } \mathrm{CTF}=20\end{array}$ & $\begin{array}{l}{ }^{*} \text { Increased } \\
{ }^{* *} \text { Increased }\end{array}$ & $\begin{array}{l}{ }^{*} \text { Decreased } \\
{ }^{* *} \text { Decreased }\end{array}$ & NA & $\begin{array}{l}\text { Nearly } \\
\text { unchanged } \\
{ }^{* *} \text { Increased }\end{array}$ & $\begin{array}{l}\text { Dai et al. } \\
\text { (2018) }\end{array}$ \\
\hline $\begin{array}{l}\text { Co (3) } \\
\text { [WI] }\end{array}$ & HZSM-5 & $\begin{array}{l}\text { Desilication by } \\
0.2 \mathrm{M} \mathrm{NaOH} \\
\text { solution while } \\
\text { assisted by } 0.3 \\
\text { piperidine }\end{array}$ & 20 & Lignite & $\begin{array}{l}\text { - } \mathrm{T}=600{ }^{\circ} \mathrm{C} \\
\text { - } \mathrm{P}=1.013 \mathrm{bar} \\
\text { - } \mathrm{VRT}=1.5 \mathrm{~s}\end{array}$ & $\begin{array}{c}\text { *Nearly } \\
\text { unchanged } \\
{ }^{* *} \text { Increased }\end{array}$ & NA & NA & $\begin{array}{l}{ }^{*} \text { Decreased } \\
{ }^{* * *} \text { Increased }\end{array}$ & $\begin{array}{l}\text { Ren et al. } \\
\text { (2018) }\end{array}$ \\
\hline $\begin{array}{l}\mathrm{Ni}(1.0) \\
{[\mathrm{WI}]}\end{array}$ & HZSM-5 & $\begin{array}{l}\text { Desilication by } \\
0.2 \mathrm{M} \mathrm{NaOH} \\
\text { solution }\end{array}$ & 40 & $\begin{array}{c}\text { Bio-oil from } \\
\text { woody } \\
\text { biomass }\end{array}$ & $\begin{array}{l}\text { - } \mathrm{T}=450{ }^{\circ} \mathrm{C} \\
\text { - } \mathrm{P}=1.013 \mathrm{bar}\end{array}$ & ${ }^{* *}$ Decreased & ${ }^{* *}$ Decreased & NA & ${ }^{* * *}$ Increased & $\begin{array}{l}\text { Veses et al. } \\
\quad(2016)\end{array}$ \\
\hline $\begin{array}{l}\mathrm{Ni}(0.1-1.0) \\
{[\mathrm{IW}]}\end{array}$ & HZSM-5 & $\begin{array}{l}\text { Desilication by } \\
0.2-1.0 \mathrm{M} \mathrm{NaOH} \\
\text { solutions and } \\
\text { washed with } 0.1 \\
\mathrm{M} \mathrm{HCl} \text { solution }\end{array}$ & NA & Rice straw & $\begin{array}{c}-\mathrm{T}=600{ }^{\circ} \mathrm{C} \\
-\mathrm{P}=1.013 \mathrm{bar} \\
-\mathrm{CTF}=20\end{array}$ & NA & $\begin{array}{l}{ }^{* *} \text { Increased for the } \\
\text { metal loadings } \\
\leq 0.5 \mathrm{wt} \% \text { and } \\
\text { decreased for }>0.5 \\
\text { wt } \%\end{array}$ & NA & NA & $\begin{array}{l}\text { Chen et al. } \\
\text { (2018a) }\end{array}$ \\
\hline $\begin{array}{l}\mathrm{Ni}(2-10) \\
{[\mathrm{WI}]}\end{array}$ & ZSM-5 & $\begin{array}{l}\text { Desilication by } \\
0.2 \mathrm{M} \mathrm{NaOH} \\
\text { solution }\end{array}$ & NA & $\begin{array}{l}\text { Torrefied corn } \\
\text { cob }\end{array}$ & $\begin{array}{c}-\mathrm{T}=550^{\circ} \mathrm{C} \\
-\mathrm{P}=1.013 \mathrm{bar} \\
\cdot \mathrm{CTF}=2\end{array}$ & $\begin{array}{l}{ }^{*} \text { Decreased } \\
{ }^{* * *} \text { Increased }\end{array}$ & $\begin{array}{l}{ }^{*} \text { Increased } \\
{ }_{* *}^{*} \text { Increased }\end{array}$ & NA & NA & $\begin{array}{l}\text { Dai et al. } \\
\text { (2019) }\end{array}$ \\
\hline $\begin{array}{l}\mathrm{Cu}(1.0) \\
{[\mathrm{WI}]}\end{array}$ & HZSM-5 & $\begin{array}{l}\text { Desilication by } \\
0.2 \mathrm{M} \mathrm{NaOH} \\
\text { solution }\end{array}$ & 40 & $\begin{array}{l}\text { Bio-oil from } \\
\text { woody } \\
\text { biomass }\end{array}$ & $\begin{array}{l}\cdot \mathrm{T}=450{ }^{\circ} \mathrm{C} \\
-\mathrm{P}=1.013 \text { bar }\end{array}$ & ${ }^{* *}$ Decreased & ${ }^{* *}$ Decreased & NA & ${ }^{* *}$ Decreased & $\begin{array}{l}\text { Veses et al. } \\
\text { (2016) }\end{array}$ \\
\hline $\begin{array}{l}\mathrm{Cu}(0.1-1.0) \\
{[\mathrm{IW]}}\end{array}$ & HZSM-5 & $\begin{array}{l}\text { Desilication by } \\
0.2-1.0 \mathrm{M} \mathrm{NaOH} \\
\text { solutions and } \\
\text { washed with } 0.1 \\
\mathrm{M} \mathrm{HCl} \text { solution }\end{array}$ & NA & Rice straw & $\begin{array}{c}\text { - } \mathrm{T}=600{ }^{\circ} \mathrm{C} \\
\text { - } \mathrm{P}=1.013 \mathrm{bar} \\
\text { - } \mathrm{CTF}=20\end{array}$ & NA & $\begin{array}{l}\text { *** Increased for the } \\
\text { metal loadings } \\
\leq 0.5 \mathrm{wt} \% \text { and } \\
\text { decreased for }>0.5 \\
\text { wt } \%\end{array}$ & NA & NA & $\begin{array}{l}\text { Chen et al. } \\
\text { (2018a) }\end{array}$ \\
\hline $\begin{array}{l}\mathrm{Zn}(9.7) \\
{[\mathrm{WI}]}\end{array}$ & HZSM-5 & $\begin{array}{l}\text { Silanization using } \\
\text { PHAPTMS }\end{array}$ & 58 & $\begin{array}{l}\text { Eucalyptus } \\
\text { woodchips }\end{array}$ & $\begin{array}{c}\text { - } \mathrm{T}=500{ }^{\circ} \mathrm{C} \\
\text { - } \mathrm{P}=1.013 \mathrm{bar} \\
-\mathrm{CTF}=0.2\end{array}$ & ${ }^{* *}$ Decreased & NA & NA & ${ }^{* *}$ Decreased & $\begin{array}{l}\text { Hernando } \\
\text { et al. (2017) }\end{array}$ \\
\hline $\begin{array}{l}\mathrm{Zn}(10) \\
{[\mathrm{WI}]}\end{array}$ & $\mathrm{H} \beta$ & $\begin{array}{l}\text { Silanization using } \\
\text { PHAPTMS }\end{array}$ & 24 & $\begin{array}{l}\text { Eucalyptus } \\
\text { woodchips }\end{array}$ & $\begin{array}{l}\text { - } \mathrm{T}=500{ }^{\circ} \mathrm{C} \\
\text { - } \mathrm{P}=1.013 \mathrm{bar} \\
\text { - } \mathrm{CTF}=0.2\end{array}$ & ${ }^{* *}$ Decreased & NA & NA & ${ }^{* *}$ Decreased & $\begin{array}{l}\text { Hernando } \\
\text { et al. (2017) }\end{array}$ \\
\hline $\begin{array}{l}\mathrm{Zn}(0.1-1.0) \\
{[\mathrm{IW}]}\end{array}$ & HZSM-5 & $\begin{array}{l}\text { Desilication by } \\
0.2-1.0 \mathrm{M} \mathrm{NaOH} \\
\text { solutions and } \\
\text { washed with } 0.1 \\
\mathrm{M} \mathrm{HCl} \text { solution }\end{array}$ & NA & Rice straw & $\begin{array}{c}\text { - } \mathrm{T}=600{ }^{\circ} \mathrm{C} \\
\text { - } \mathrm{P}=1.013 \mathrm{bar} \\
\text { - } \mathrm{CTF}=20\end{array}$ & NA & ${ }^{* *}$ Decreased & NA & NA & $\begin{array}{l}\text { Chen et al. } \\
\text { (2018a) }\end{array}$ \\
\hline $\begin{array}{l}\mathrm{Ga}(1.0) \\
{[\mathrm{WI}]}\end{array}$ & HZSM-5 & $\begin{array}{l}\text { Desilication by } \\
0.3 \mathrm{M} \mathrm{NaOH} \\
\text { solution }\end{array}$ & NA & Cellulose & $\begin{array}{c}\text { - } \mathrm{T}=500{ }^{\circ} \mathrm{C} \\
-\mathrm{P}=1.013 \mathrm{bar} \\
-\mathrm{RT}=30 \mathrm{~s} \\
\text { - } \mathrm{CTF}=20\end{array}$ & $\begin{array}{l}{ }^{*} \text { Increased } \\
{ }^{* *} \text { Increased }\end{array}$ & $\begin{array}{l}{ }^{*} \text { Increased } \\
{ }_{* *}^{* *} \text { Increased }\end{array}$ & NA & $\begin{array}{l}{ }^{*} \text { Decreased } \\
{ }_{* *} \text { Decreased }\end{array}$ & $\begin{array}{l}\text { Dai et al. } \\
\text { (2018) }\end{array}$ \\
\hline $\begin{array}{l}\mathrm{Ga}(0.1-1.0) \\
{[\mathrm{IW}]}\end{array}$ & HZSM-5 & $\begin{array}{l}\text { Desilication by } \\
0.2-1.0 \mathrm{M} \mathrm{NaOH} \\
\text { solutions and } \\
\text { washed with } 0.1 \\
\mathrm{M} \mathrm{HCl} \text { solution }\end{array}$ & NA & Rice straw & $\begin{array}{c}\text { - } \mathrm{T}=600{ }^{\circ} \mathrm{C} \\
-\mathrm{P}=1.013 \mathrm{bar} \\
-\mathrm{CTF}=20\end{array}$ & NA & $\begin{array}{l}{ }^{* *} \text { Increased for the } \\
\text { metal loadings } \\
\leq 0.5 \mathrm{wt} \% \text { and } \\
\text { decreased for }>0.5 \\
\text { wt } \%\end{array}$ & NA & NA & $\begin{array}{l}\text { Chen et al. } \\
\text { (2018a) }\end{array}$ \\
\hline $\begin{array}{l}\mathrm{Zr}(5) \\
{[\mathrm{WI}]}\end{array}$ & HZSM-5 & $\begin{array}{l}\text { Desilication by } \\
0.2 \mathrm{M} \mathrm{NaOH} \\
\text { solution while } \\
\text { assisted by } 0.3 \\
\text { piperidine } \\
\end{array}$ & 20 & Lignite & $\begin{array}{l}\text { - } \mathrm{T}=600{ }^{\circ} \mathrm{C} \\
\text { - } \mathrm{P}=1.013 \mathrm{bar} \\
\text { - } \mathrm{VRT}=1.5 \mathrm{~s}\end{array}$ & $\begin{array}{l}{ }^{*} \text { Decreased } \\
{ }^{* *} \text { Increased }\end{array}$ & NA & NA & $\begin{array}{l}{ }^{*} \text { Decreased } \\
{ }^{* *} \text { Increased }\end{array}$ & $\begin{array}{l}\text { Ren et al. } \\
\text { (2018) }\end{array}$ \\
\hline
\end{tabular}


Table 8.

continued.

\begin{tabular}{|c|c|c|c|c|c|c|c|c|c|c|}
\hline $\begin{array}{l}\text { Metal(s) (wt\%) } \\
\text { [Loading } \\
\text { method] }\end{array}$ & $\begin{array}{l}\text { Zeolite } \\
\text { framework }\end{array}$ & Synthesis method & $\begin{array}{c}\mathrm{Si} / \mathrm{Al} \text { of } \\
\text { synthesized } \\
\text { zeolite }\end{array}$ & Feedstock (s) & $\begin{array}{l}\text { Operating } \\
\text { conditions }\end{array}$ & $\begin{array}{c}\text { Change in } \\
\text { oxygenates } \\
\text { yield }\end{array}$ & $\begin{array}{l}\text { Change in } \\
\text { aromatic } \\
\text { hydrocarbons } \\
\text { yield }\end{array}$ & $\begin{array}{l}\text { Change in } \\
\text { olefins yield }\end{array}$ & $\begin{array}{c}\text { Change in } \\
\text { coke } \\
\text { formation }\end{array}$ & Reference \\
\hline $\begin{array}{l}\text { Sn (1.0) } \\
\text { [WI] }\end{array}$ & HZSM-5 & $\begin{array}{l}\text { Desilication by } \\
0.2 \mathrm{M} \mathrm{NaOH} \\
\text { solution }\end{array}$ & 40 & $\begin{array}{l}\text { Bio-oil from } \\
\text { woody } \\
\text { biomass }\end{array}$ & $\begin{aligned} &-\mathrm{T}=450{ }^{\circ} \mathrm{C} \\
&-\mathrm{P}=1.013 \mathrm{bar}\end{aligned}$ & $\begin{array}{l}{ }^{* *} \text { Nearly } \\
\text { unchanged }\end{array}$ & ${ }^{* *}$ Decreased & NA & $\begin{array}{l}{ }^{* *} \text { Nearly } \\
\text { unchanged }\end{array}$ & $\begin{array}{l}\text { Veses et al. } \\
\text { (2016) }\end{array}$ \\
\hline $\begin{array}{l}\mathrm{La}(5.0) \\
{[\mathrm{WI}]}\end{array}$ & HZSM-5 & $\begin{array}{l}\text { Desilication by } \\
3.0 \mathrm{M} \mathrm{Na}_{2} \mathrm{CO}_{3} \\
\text { solution }\end{array}$ & NA & Rape straw & $\begin{array}{c}\cdot \mathrm{T}=500{ }^{\circ} \mathrm{C} \\
\cdot \mathrm{P}=5 \mathrm{kPa} \\
\text { (vacuum) } \\
\bullet \mathrm{HR}=20^{\circ} \mathrm{C} / \mathrm{min} \\
\cdot \mathrm{RT}=45 \mathrm{~min} \\
\cdot \mathrm{CTF}=20\end{array}$ & $\begin{array}{l}{ }^{*} \text { Decreased } \\
{ }_{* * *}^{* *} \text { Decreased }\end{array}$ & $\begin{array}{l}\text { "Increased } \\
{ }^{* *} \text { Increased }\end{array}$ & NA & $\begin{array}{l}{ }^{*} \text { Decreased } \\
{ }^{* * *} \text { Decreased }\end{array}$ & $\begin{array}{l}\text { Li et al. } \\
\text { (2018) }\end{array}$ \\
\hline $\begin{array}{l}\mathrm{Ce}(1.92) \\
{[\mathrm{DG}]}\end{array}$ & HZSM-5 & $\begin{array}{l}\text { SAC of the dry gel } \\
\text { performed by dual } \\
\text { templating } \\
\text { (SDA=TPAOH, } \\
\text { surfactant=tribloc } \\
\text { k copolymer) }\end{array}$ & 55 & Glucose & $\begin{array}{l}-\mathrm{T}=600{ }^{\circ} \mathrm{C} \\
-\mathrm{RT}=360 \mathrm{~s} \\
-\mathrm{CTF}=9.0\end{array}$ & $\begin{array}{l}{ }_{\text {*** Increased }}^{*} \\
\text { Nearly } \\
\text { unchanged }\end{array}$ & $\begin{array}{l}{ }^{*} \text { Decreased } \\
{ }_{* * *}^{*} \text { Decreased }\end{array}$ & NA & $\begin{array}{l}{ }^{*} \text { Decreased } \\
{ }^{* * *} \text { Decreased }\end{array}$ & $\begin{array}{l}\text { Neumann } \\
\text { and Hicks } \\
\text { (2012b) }\end{array}$ \\
\hline $\begin{array}{l}\mathrm{Ce}(2.75) \\
{[\mathrm{IW]}}\end{array}$ & HZSM-5 & $\begin{array}{l}\text { SAC of the dry gel } \\
\text { performed by dual } \\
\text { templating } \\
\text { (SDA=TPAOH, } \\
\text { surfactant=tribloc } \\
\text { k copolymer) }\end{array}$ & 49 & Glucose & $\begin{array}{l}-\mathrm{T}=600{ }^{\circ} \mathrm{C} \\
-\mathrm{RT}=360 \mathrm{~s} \\
-\mathrm{CTF}=9.0\end{array}$ & $\begin{array}{l}{ }^{*} \text { Increased } \\
{ }_{* * *}^{*} \text { Decreased }\end{array}$ & $\begin{array}{l}{ }^{*} \text { Decreased } \\
{ }_{* * *}^{*} \text { Decreased }\end{array}$ & NA & $\begin{array}{l}\text { "Increased } \\
{ }^{* *} \text { Increased }\end{array}$ & $\begin{array}{l}\text { Neumann } \\
\text { and Hicks } \\
\text { (2012b) }\end{array}$ \\
\hline $\begin{array}{l}\mathrm{Ce}(1.05) \\
{[\mathrm{IEx}]}\end{array}$ & HZSM-5 & $\begin{array}{l}\text { SAC of the dry gel } \\
\text { performed by dual } \\
\text { templating } \\
\text { (SDA=TPAOH, } \\
\text { surfactant= } \\
\text { triblock } \\
\text { copolymer) }\end{array}$ & 50 & Glucose & $\begin{array}{l}-\mathrm{T}=600{ }^{\circ} \mathrm{C} \\
-\mathrm{RT}=360 \mathrm{~s} \\
\text { - } \mathrm{CTF}=9.0\end{array}$ & $\begin{array}{l}{ }_{* * *}^{*} \text { Increased } \\
{ }^{* *} \text { Decreased }\end{array}$ & $\begin{array}{l}\text { *Increased } \\
{ }^{* * *} \text { Increased }\end{array}$ & NA & $\begin{array}{l}{ }^{*} \text { Nearly } \\
\text { unchanged } \\
{ }^{* *} \text { Nearly } \\
\text { unchanged }\end{array}$ & $\begin{array}{l}\text { Neumann } \\
\text { and Hicks } \\
(2012 \mathrm{~b})\end{array}$ \\
\hline $\begin{array}{l}\mathrm{Zr}(1-15) \text { and } \\
\mathrm{Co}(3) \\
{[\mathrm{WI}]}\end{array}$ & HZSM-5 & $\begin{array}{l}\text { Desilication by } \\
0.2 \mathrm{M} \mathrm{NaOH} \\
\text { solution while } \\
\text { assisted by } 0.3 \\
\text { piperidine }\end{array}$ & 20 & Lignite & $\begin{array}{l}\text { - } \mathrm{T}=600{ }^{\circ} \mathrm{C} \\
\text { - } \mathrm{P}=1.013 \mathrm{bar} \\
\text { - VRT }=1.5 \mathrm{~s}\end{array}$ & $\begin{array}{l}\text { "Increased } \\
{ }^{* * *} \text { Increased }\end{array}$ & NA & NA & $\begin{array}{l}{ }^{*} \text { Decreased } \\
{ }^{* * *} \text { Increased }\end{array}$ & $\begin{array}{l}\text { Ren et al. } \\
\text { (2018) }\end{array}$ \\
\hline
\end{tabular}

* Change in yield compared to parent microporous zeolite.

** Change in yield compared to nonmetallic hierarchical zeolite.

*** Abbreviations: CFT: Catalyst-to-feed ratio; CTAB: hexadecyltrimethylammonium bromide; DG: Dry-gel method; HR: Heating rate; IEx: Ion-exchange method; IW: Incipient wetness method; NA: Not available; P: Pressure; PHAPTMS: 3-(Phenylamino)propyltrimethoxysilane; RT: Residence time; SAC: Steam assisted crystallization; SDA: Structure-directing agent; T: Temperature; TPAOH: Tetrapropylammonium hydroxide; VRT: Vapor residence time; WI: Wet impregnation method.

found that the aromatic yield decreased as the metal loading increased. This could be ascribed to the metal atoms exchange with $\mathrm{H}^{+}$on the catalyst surface at higher metal loadings, leading to decreases in the acidity and cracking capability of the catalyst.

\subsection{Gallium loading}

Dai et al. (2018) proved that the impregnation of hierarchical HSM-5 zeolites with Ga species imparted a positive effect on aromatic yields. They found that this metal-modified hierarchical zeolite tended to form BTX compounds and alkylbenzenes at the expense of reducing poly-aromatic hydrocarbons.

\subsection{Lanthanum loading}

Li et al. (2018) conducted vacuum pyrolysis of rape straw over La-modified hierarchical HZSM- 5 zeolites desilicated by a $3 \mathrm{M} \mathrm{Na}_{2} \mathrm{CO}_{3}$ solution. Compared to the parent HZSM-5 and nonmetallic hierarchical HZSM-5 zeolites, the metal-incorporated catalyst yielded the largest quantity of hydrocarbons (i.e., $\sim 50 \%$ ) while showed the lowest tendency toward carbonyl species (about $11 \%)$. Moreover, it had the highest selectivity toward mono-aromatic hydrocarbons, while generating the minimum amount of coke $(\sim 11 \%)$.

\subsection{Cerium loading}

One of the potential incentives for cerium introduction in a catalytic framework is to mitigate coke formation. Nevertheless, it should be noted that the incorporation of cerium into the zeolite structure shifts product selectivity from aromatic hydrocarbons toward oxygenated compounds. Neumann and Hicks (2012b) used a Ce-incorporated hierarchical HZSM-5 zeolite in the CFP of lignocellulosic biomass. They figured out that the catalyst had a shifted tendency toward valuable oxygenates (i.e., furans, ketones, and aldehydes) compared with the parent hierarchical HZSM-5 zeolite mainly producing mono-aromatic hydrocarbons (i.e., benzene, toluene, and xylenes). In addition, the Ce/hierarchical HZSM-5 zeolite reduced the amount of coke formation. It was also revealed that the intraframework Ce-incorporated hierarchical HZSM-5 zeolite could significantly promote the ketonization of acetic acid to yield much higher quantities of acetone compared to both parent microporous HZSM-5 zeolite and nonmetal-containing hierarchical HZSM-5 zeolite (Fig. 16).

\subsection{Magnesium loading}

Veses et al. (2016) compared different hierarchical ZSM-5 zeolites modified with metal cations such as $\mathrm{Sn}, \mathrm{Cu}, \mathrm{Ni}$, and $\mathrm{Mg}$ in the upgrading 
<smiles>CC(=O)OC(C)=O</smiles>

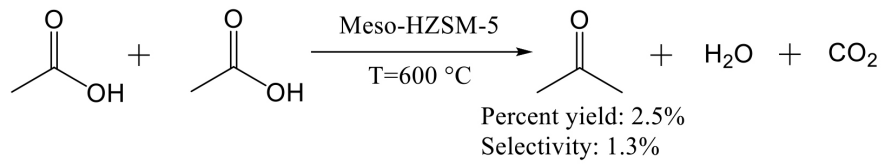

Fig. 16. The yields of acetone through the ketonization of acetic acid over hierarchical HZSM-5 zeolites with and without cerium. Redrawn with permission from Neumann and Hicks (2012b). Copyright@ 2012 American Chemical Society.

of wood-based bio-oil. The magnesium-incorporated hierarchical zeolite exhibited the highest performance in terms of oxygen and acidity reduction, which consequently resulted in the best fuel quality (Fig. 17). This was ascribed to the Lewis acid sites formed after the deposition of Mg cations at the ionexchange sites which could promote the ketonization reaction of carboxylic acids with aldehydes. Following the Mg-loaded hierarchical ZSM-5 zeolite, the zeolite impregnated with $\mathrm{Cu}$ metal possessed the highest deoxygenation rate. This catalyst favored the removal of oxygen through decarbonylation of carboxylic acids to aldehydes on $\mathrm{Cu}$ cations introduced at the ion-exchange sites. Among the metal-loaded hierarchical-structured zeolites, the Ni- and Snincorporated catalysts exhibited the lowest deoxygenation performances which could be explained by their low cation introduction at ion-exchange sites. Hernando et al. (2017) revealed that the addition of Mg to both hierarchical HZSM-5 and $\mathrm{H} \beta$ zeolites resulted in the production of bio-oils with more favorable energy contents and deoxygenation rates compared with those loaded with $\mathrm{Zn}$. This could be ascribed to the superior balance between Lewis acid and basic sites in response to the $\mathrm{Mg}$ loading.

\subsection{Palladium loading}

Hunns et al. (2016) explored the influence of mesoporosity and acidic strength of bifunctional hierarchical Pd/ZSM-5 catalysts on the hydrodeoxygenation of m-cresol. These catalysts exhibited high activity and selectivity values toward the production of methylcyclohexane aliphatic compounds. Based on mass normalized acid site densities obtained by the $\mathrm{NH}_{3}$ chemisorption analysis, it was revealed that the hierarchical mesoporous $\mathrm{Pd} / \mathrm{ZSM}-5$ with the $\mathrm{Si} / \mathrm{Al}$ ratio of 30 possessed a slightly higher acid loading compared to its conventional microporous counterpart (i.e., 0.35 against 0.3 mmol g${ }^{-1}$, respectively). However, further increases in the $\mathrm{Si} / \mathrm{Al}$ atomic ratio diminished the acid sites to about one third (i.e., 0.13). It was perceived that varying the $\mathrm{Si} / \mathrm{Al}$ atomic ratio only influenced the number of acid sites, whereas their strength remained unaffected (Hunns et al., 2016).

\subsection{Bi-metal loading}

Ren et al. (2018) observed that the bi-metallic Zr-Co/hierarchical HSZM-5 had a higher total acidity than the Co/hierarchical HSZM-5. The incorporation of the bimetallic $\mathrm{Zr}$-Co species facilitated the transfer of hydrogen from pyrolysis intermediates and increased the pace of the cracking and deoxygenation reactions. The co-loading of $5 \mathrm{wt} \% \mathrm{Zr}$ and $3 \mathrm{wt} \% \mathrm{Co}$ on the hierarchical HZSM-5 zeolite treated by $0.2 \mathrm{M} \mathrm{NaOH}+0.3 \mathrm{M}$ piperidine was found to result in the most favorable performance. More specifically, this catalyst increased the selectivity toward light aromatics, while it mitigated the organic oxygen compounds and macromolecular species.

\section{Concluding remarks and future prospects}

Microporous zeolites are known as reliable frameworks in designing advanced catalysts used for upgrading pyrolytic vapors. These materials can promote the reactions of cracking, aromatization, alkylation, and
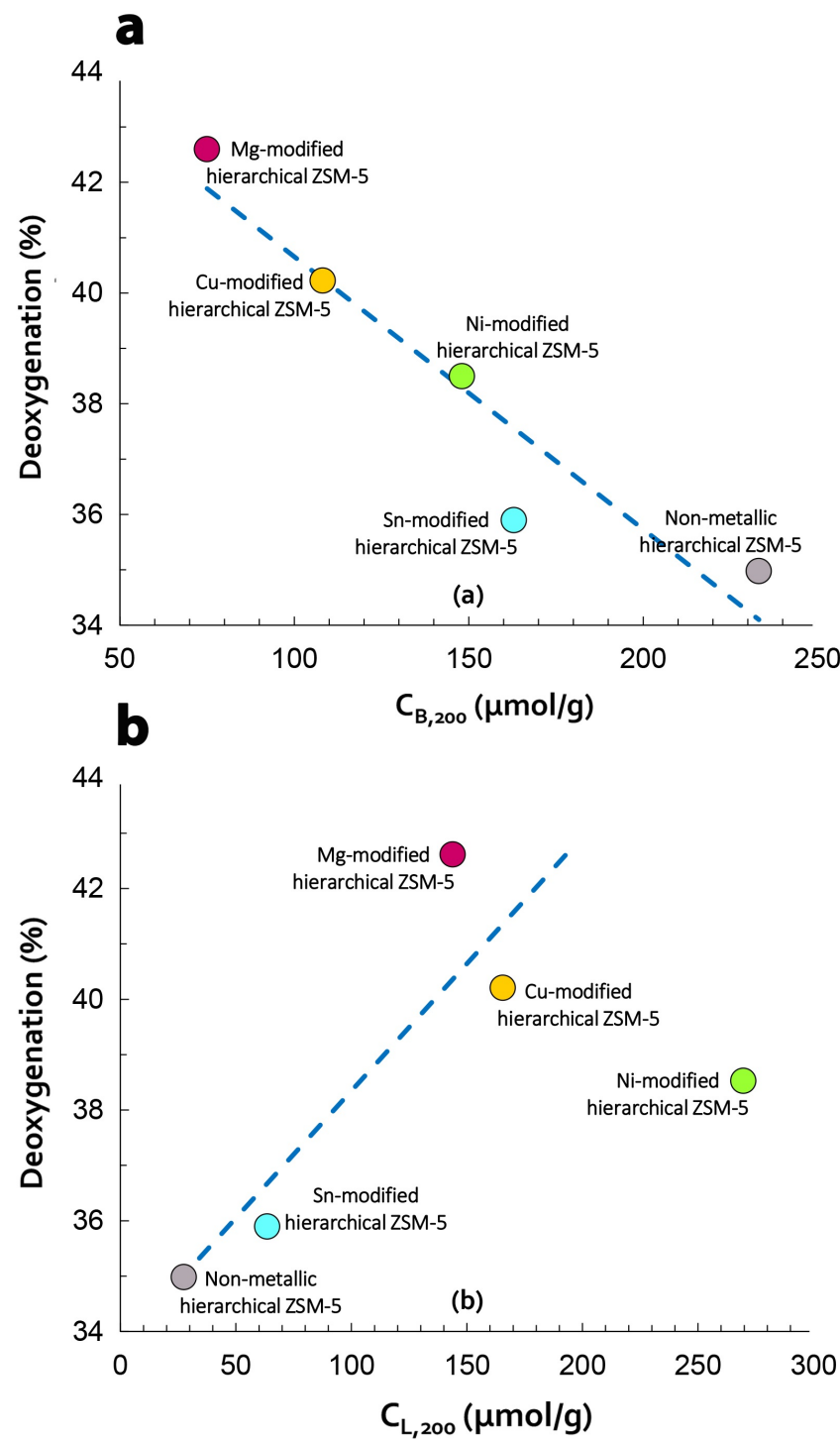

Fig. 17. Changes in the percentage of deoxygenation during the upgrading of wood-based bio-oil as a function of (a) Bronsted acidity and (b) Lewis acidity of metalloaded/nonmetallic hierarchical ZSM-5 zeolites. Redrawn with permission from Veses et al. (2016). Copyright $\odot 2016$ American Chemical Society.

hydrodeoxygenation. However, the nano-size scale of microporous zeolites limits the diffusion of the molecules which are larger than the channel size of micropores. To address this challenge, hierarchical zeolites have emerged as a "trump card" for converting oxygen-rich bio-oils to valuable products by serving two levels of porosity, i.e., micropore and mesopore structures. In fact, the secondary mesoporosity of hierarchical zeolites is seen as "hitting two birds with one stone", i.e., enhancing the accessibility to acid sites and decreasing coke formation with a single modification. However, the principal obstacles to using hierarchical zeolites in large scale is the complexity and cost of the synthesis process. Nonetheless, the capability of hierarchical zeolites for massive production of valuable chemicals can alleviate their high fabrication costs. Among the different synthesis methods applied for zeolite modification, the desilication using alkaline solutions is a promising technique to form a micro-mesoporous hierarchical network in zeolites. Unlike other hierarchicalization methods, this approach is highly advantageous due to its simplicity, efficiency, costeffectiveness, and scalability. 
In the alkali-based desilication process, the hydroxide anions leach out of the $\mathrm{Si}$ atoms contained in zeolite structure to facilitate the formation of intracrystalline mesoporosity. However, the synthesis conditions have remarkable impacts on the acidity and textural properties of the final hierarchical zeolites, significantly affecting their catalyzing characteristics. For instance, there is a consensus among researchers that the optimal concentration of $\mathrm{NaOH}$ solution should be $0.3 \mathrm{M}$ since this can preserve the crystallinity of parent zeolite and increase the mesopore surface and volume. Moreover, in terms of product distribution in the CFP process, the desilication technique using $0.3 \mathrm{M} \mathrm{NaOH}$ can synthesize hierarchical zeolites favoring the production of mono-aromatic hydrocarbons. It should be noted that there is a lack of research works with a focus on the influence of advanced synthesis procedures on the performance of biomass CFP. Therefore, a proportion of future studies should be dedicated to analyzing these effects.

It is important to note that the formation of secondary mesoporosity in hierarchical zeolites can provide a befitted room for the deposition of additional active sites such as metal species. The incorporated metals can be uniformly dispersed both in the micro-meso network and on the external surface of hierarchical zeolites, boosting their catalytic activity. Although the utilization of metal-loaded hierarchical zeolites is not a first-hand issue in advanced applications, the resultant compounds have emerged in a handful of literature in the field of catalytic pyrolysis. The present review covered most of the studies on the application of metal-loaded hierarchical zeolites in biomass catalytic pyrolysis. As a final suggestion, future research works should also be directed toward the assessment of the CFP performance in the presence of hierarchical zeolites impregnated by different mono- and bi-metals.

\section{References}

[1] Abdullah, B., Muhammad, S.A.F.a.S., Shokravi, Z., Ismail, S., Kassim, K.A., Mahmood, A.N., Aziz, M.M.A., 2019. Fourth generation biofuel: A review on risks and mitigation strategies. Renew. Sustain. Energy Rev. $107,37-50$

[2] Aghbashlo, M., Tabatabaei, M., Nadian, M.H., Davoodnia, V., Soltanian, S., 2019. Prognostication of lignocellulosic biomass pyrolysis behavior using ANFIS model tuned by PSO algorithm. Fuel 253, 189-198.

[3] Álvarez-Chávez, B.J., Godbout, S., Le Roux, É., Palacios, J.H., Raghavan, V., 2019. Bio-oil yield and quality enhancement through fast pyrolysis and fractional condensation concepts. Biofuel Res. J. 6(4), 1054-1064.

[4] Bertero, M., Sedran, U., 2016. Immediate catalytic upgrading of soybean shell bio-oil. Energy 94, 171-179.

[5] Bi, Y., Lei, X., Xu, G., Chen, H., Hu, J., 2018. Catalytic fast pyrolysis of kraft lignin over hierarchical HZSM-5 and H $\beta$ zeolites. Catalysts 8(2), 82.

[6] Bu, L., Nimlos, M.R., Robichaud, D.J., Kim, S., 2018. Diffusion of aromatic hydrocarbons in hierarchical mesoporous H-ZSM-5 zeolite. Catal. Today 312, 73-81

[7] Chang, C.-C., Teixeira, A.R., Li, C., Dauenhauer, P.J., Fan, W., 2013. Enhanced molecular transport in hierarchical silicalite-1. Langmuir 29(45), 13943-13950.

[8] Chen, H., Cheng, H., Zhou, F., Chen, K., Qiao, K., Lu, X., Ouyang, P., Fu, J., 2018a. Catalytic fast pyrolysis of rice straw to aromatic compounds over hierarchical HZSM-5 produced by alkali treatment and metal-modification. J. Anal. Appl. Pyrolysis 131, 76-84

[9] Chen, H., Shi, X., Zhou, F., Ma, H., Qiao, K., Lu, X., Fu, J., Huang, H., 2018b. Catalytic fast pyrolysis of cellulose to aromatics over hierarchical nanocrystalline ZSM-5 zeolites prepared using sucrose as a template. Catal. Commun. 110, 102-105

[10] Chen, H., Wang, Q., Zhang, X., Wang, L., 2014. Hydroconversion of jatropha oil to alternative fuel over hierarchical ZSM-5. Ind. Eng. Chem. Res. 53(51), 19916-19924.

[11] Chen, H., Wydra, J., Zhang, X., Lee, P.-S., Wang, Z., Fan, W., Tsapatsis, M., 2011. Hydrothermal synthesis of zeolites with three-dimensionally ordered mesoporous-imprinted structure. J. Am. Chem. Soc. 133(32), 12390-12393.
[12] Cheng, Y.T., Jae, J., Shi, J., Fan, W., Huber, G.W., 2012. Production of renewable aromatic compounds by catalytic fast pyrolysis of lignocellulosic biomass with bifunctional Ga/ZSM-5 catalysts. Angew. Chem. Int. Ed. 51(6), 1387-1390.

[13] Dai, G., Wang, S., Zou, Q., Huang, S., 2018. Improvement of aromatics production from catalytic pyrolysis of cellulose over metalmodified hierarchical HZSM-5. Fuel Process. Technol. 179, 319-323

[14] Dai, L., Wang, Y., Liu, Y., Ruan, R., Duan, D., Zhao, Y., Yu, Z., Jiang, L., 2019. Catalytic fast pyrolysis of torrefied corn cob to aromatic hydrocarbons over Ni-modified hierarchical ZSM-5 catalyst. Bioresour. Technol. 272, 407-414.

[15] Dickerson, T., Soria, J., 2013. Catalytic fast pyrolysis: a review. Energies 6(1), 514-538

[16] Ding, K., Zhong, Z., Wang, J., Zhang, B., Addy, M., Ruan, R., 2017. Effects of alkali-treated hierarchical HZSM-5 zeolites on the production of aromatic hydrocarbons from catalytic fast pyrolysis of waste cardboard. J. Anal. Appl. Pyrolysis 125, 153-161.

[17] Escola, J., Aguado, J., Serrano, D., Briones, L., Díaz de Tuesta, J. Calvo, R., Fernandez, E., 2012. Conversion of polyethylene into transportation fuels by the combination of thermal cracking and catalytic hydroreforming over Ni-supported hierarchical beta zeolite. Energ. Fuel. 26(6), 3187-3195.

[18] Escola, J., Aguado, J., Serrano, D., García, A., Peral, A., Briones, L., Calvo, R., Fernandez, E., 2011. Catalytic hydroreforming of the polyethylene thermal cracking oil over $\mathrm{Ni}$ supported hierarchical zeolites and mesostructured aluminosilicates. Appl. Catal. BEnviron. 106(3-4), 405-415.

[19] Feliczak-Guzik, A., 2018. Hierarchical zeolites: Synthesis and catalytic properties. Microporous Mesoporous Mater. 259, 33-45.

[20] Groen, J.C., Jansen, J.C., Moulijn, J.A., Pérez-Ramírez, J., 2004 Optimal aluminum-assisted mesoporosity development in MFI zeolites by desilication. J. Phys. Chem. B 108(35), 13062-13065.

[21] Groen, J.C.. Moulijn, J.A., Pérez-Ramírez, J., 2006. Desilication: on the controlled generation of mesoporosity in MFI zeolites. J. Mater. Chem. 16(22), 2121-2131

[22] Groen, J.C., Zhu, W., Brouwer, S., Huynink, S.J., Kapteijn, F. Moulijn, J.A., Pérez-Ramírez, J., 2007. Direct demonstration of enhanced diffusion in mesoporous ZSM-5 zeolite obtained via controlled desilication. J. Am. Chem. Soc. 129(2), 355-360.

[23] Hernando, H., Moreno, I., Fermoso, J., Ochoa-Hernández, C., Pizarro, P., Coronado, J.M., Čejka, J., Serrano, D.P., 2017. Biomass catalytic fast pyrolysis over hierarchical ZSM-5 and Beta zeolites modified with $\mathrm{Mg}$ and $\mathrm{Zn}$ oxides. Biomass Convers. Biorefin. 7(3), 289-304.

[24] Hoff, T.C., Gardner, D.W., Thilakaratne, R., Proano-Aviles, J., Brown, R.C., Tessonnier, J.-P., 2017. Elucidating the effect of desilication on aluminum-rich ZSM-5 zeolite and its consequences on biomass catalytic fast pyrolysis. Appl. Catal. A-Gen. 529, 68-78.

[25] Huber, G.W., Iborra, S., Corma, A., 2006. Synthesis of transportation fuels from biomass: chemistry, catalysts, and engineering. Chem. Rev. 106(9), 4044-4098

[26] Hunns, J.A., Arroyo, M., Lee, A.F., Serrano, D., Wilson, K., 2016. Hierarchical mesoporous Pd/ZSM-5 for the selective catalytic hydrodeoxygenation of m-cresol to methylcyclohexane. Catal. Sci. Technol. 6(8), 2560-2564

[27] Ibarra-Gonzalez, P., Rong, B.-G., 2019. A review of the current state of biofuels production from lignocellulosic biomass using thermochemical conversion routes. Chin. J. Chem. Eng. 27(7), 15231535.

[28] Iisa, K., French, R.J., Orton, K.A., Yung, M.M., Johnson, D.K., ten Dam, J., Watson, M.J., Nimlos, M.R., 2016. In situ and ex situ catalytic pyrolysis of pine in a bench-scale fluidized bed reactor system. Energ. Fuel. 30(3), 2144-2157.

[29] Jae, J., Tompsett, G.A., Foster, A.J., Hammond, K.D., Auerbach, S.M., Lobo, R.F., Huber, G.W., 2011. Investigation into the shape selectivity of zeolite catalysts for biomass conversion. J. Catal $279(2), 257-268$ 
[30] Jia, L., Raad, M., Hamieh, S., Toufaily, J., Hamieh, T., Bettahar, M., Mauviel, G., Tarrighi, M., Pinard, L., Dufour, A., 2017. Catalytic fast pyrolysis of biomass: superior selectivity of hierarchical zeolites to aromatics. Green Chem. 19(22), 5442-5459.

[31] Jia, Y., Wang, J., Zhang, K., Chen, G., Yang, Y., Liu, S., Ding, C., Meng, Y., Liu, P., 2018. Hierarchical ZSM-5 zeolite synthesized via dry gel conversion-steam assisted crystallization process and its application in aromatization of methanol. Powder Technol. 328, 415-429.

[32] Khan, W., Jia, X., Wu, Z., Choi, J., Yip, A.C., 2019. Incorporating hierarchy into conventional zeolites for catalytic biomass conversions: A review. Catalysts 9(2), 127 .

[33] Kim, Y.H., Lee, K.H., Nam, C.M., Lee, J.S., 2012. Formation of hierarchical pore structures in $\mathrm{Zn} / \mathrm{ZSM}-5$ to improve the catalyst stability in the aromatization of branched olefins. ChemCatChem 4(8), 11431153 .

[34] Kumar, R., Strezov, V., Lovell, E., Kan, T., Weldekidan, H., He, J., Jahan, S., Dastjerdi, B., Scott, J., 2019. Enhanced bio-oil deoxygenation activity by $\mathrm{Cu} /$ zeolite and $\mathrm{Ni} /$ zeolite catalysts in combined in-situ and exsitu biomass pyrolysis. J. Anal. Appl. Pyrolysis 140, 148-160.

[35] Li, B., Ou, L., Dang, Q., Meyer, P., Jones, S., Brown, R., Wright, M., 2015. Techno-economic and uncertainty analysis of in situ and ex situ fast pyrolysis for biofuel production. Bioresour. Technol. 196, 49-56

[36] Li, J., Li, X., Zhou, G., Wang, W., Wang, C., Komarneni, S., Wang, Y., 2014a. Catalytic fast pyrolysis of biomass with mesoporous ZSM-5 zeolites prepared by desilication with $\mathrm{NaOH}$ solutions. Appl. Catal. AGen. 470, 115-122.

[37] Li, K., Valla, J., Garcia-Martinez, J., 2014b. Realizing the commercial potential of hierarchical zeolites: new opportunities in catalytic cracking. ChemCatChem 6(1), 46-66.

[38] Li, X., Zhang, X., Shao, S., Dong, L., Zhang, J., Hu, C., Cai, Y., 2018. Catalytic upgrading of pyrolysis vapor from rape straw in a vacuum pyrolysis system over La/HZSM-5 with hierarchical structure. Bioresour. Technol. 259, 191-197.

[39] Li, Z., Zhong, Z., Zhang, B., Wang, W., Seufitelli, G.V., Resende, F.L., 2020. Catalytic fast co-pyrolysis of waste greenhouse plastic films and rice husk using hierarchical micro-mesoporous composite molecular sieve. Waste Manage. 102, 561-568.

[40] Li, Z., Zhong, Z., Zhang, B., Wang, W., Wu, W., 2019. Catalytic fast pyrolysis of rice husk over hierarchical micro-mesoporous composite molecular sieve: analytical Py-GC/MS study. J. Anal. Appl. Pyrolysis $138,103-113$.

[41] Liang, J., Morgan Jr, H.M., Liu, Y., Shi, A., Lei, H., Mao, H., Bu, Q., 2017. Enhancement of bio-oil yield and selectivity and kinetic study of catalytic pyrolysis of rice straw over transition metal modified ZSM-5 catalyst. J. Anal. Appl. Pyrolysis 128, 324-334.

[42] Liu, C., Wang, H., Karim, A.M., Sun, J., Wang, Y., 2014. Catalytic fast pyrolysis of lignocellulosic biomass. Chem. Soc. Rev. 43(22), 75947623

[43] Mihalcik, D.J., Mullen, C.A., Boateng, A.A., 2011. Screening acidic zeolites for catalytic fast pyrolysis of biomass and its components. J. Anal. Appl. Pyrolysis 92(1), 224-232.

[44] Mondal, A.K., Qin, C., Ragauskas, A.J., Ni, Y., Huang, F., 2020. Conversion of Loblolly pine biomass residues to bio-oil in a two-step process: Fast pyrolysis in the presence of zeolite and catalytic hydrogenation. Ind. Crops Prod. 148, 112318

[45] Mullen, C.A., Tarves, P.C., Raymundo, L.M., Schultz, E.L., Boateng, A.A., Trierweiler, J.O., 2018. Fluidized bed catalytic pyrolysis of eucalyptus over HZSM-5: effect of acid density and gallium modification on catalyst deactivation. Energ. Fuel. 32(2), 1771-1778.

[46] Murugappan, K., Mukarakate, C., Budhi, S., Shetty, M., Nimlos, M.R., Román-Leshkov, Y., 2016. Supported molybdenum oxides as effective catalysts for the catalytic fast pyrolysis of lignocellulosic biomass. Green Chem. 18(20), 5548-5557.

[47] Neumann, G.T. Hicks, J.C., 2012a. Effects of cerium and aluminum in cerium-containing hierarchical HZSM-5 catalysts for biomass upgrading. Top. Catal. 55(3-4), 196-208.

[48] Neumann, G.T., Hicks, J.C., 2012b. Novel hierarchical ceriumincorporated MFI zeolite catalysts for the catalytic fast pyrolysis of lignocellulosic biomass. ACS Catal. 2(4), 642-646.
[49] Olarte, M.V., Padmaperuma, A.B., Ferrell III, J.R., Christensen, E.D., Hallen, R.T., Lucke, R.B., Burton, S.D., Lemmon, T.L., Swita, M.S., Fioroni, G., 2017. Characterization of upgraded fast pyrolysis oak oil distillate fractions from sulfided and non-sulfided catalytic hydrotreating. Fuel 202, 620-630.

[50] Önal, E., Uzun, B.B., Pütün, A.E., 2014. Bio-oil production via copyrolysis of almond shell as biomass and high density polyethylene. Energy Convers. Manag. 78, 704-710.

[51] Primo, A., Garcia, H., 2014. Zeolites as catalysts in oil refining. Chem. Soc. Rev. 43(22), 7548-7561.

[52] Puértolas, B., García-Andújar, L., García, T., Navarro, M., Mitchell, S., Pérez-Ramírez, J., 2014. Bifunctional Cu/H-ZSM-5 zeolite with hierarchical porosity for hydrocarbon abatement under cold-star conditions. Appl. Catal. B-Environ. 154, 161-170.

[53] Puértolas, B., Veses, A., Callén, M.S., Mitchell, S., García, T., PérezRamírez, J., 2015. Porosity-acidity interplay in hierarchical ZSM-5 zeolites for pyrolysis oil valorization to aromatics. ChemSusChem 8(19), 3283-3293

[54] Pyl, S.P., Hou, Z., Van Geem, K.M., Reyniers, M.F., Marin, G.B. Klein, M.T., 2011. Modeling the composition of crude oil fractions using constrained homologous series. Ind. Eng. Chem. Res. 50(18), 10850-10858

[55] Qiao, K., Shi, X., Zhou, F., Chen, H., Fu, J., Ma, H., Huang, H., 2017. Catalytic fast pyrolysis of cellulose in a microreactor system using hierarchical zsm-5 zeolites treated with various alkalis. Appl. Catal. A-Gen. 547, 274-282.

[56] Qiao, K., Zhou, F., Han, Z., Fu, J., Ma, H., Wu, G., 2019. Synthesis and physicochemical characterization of hierarchical ZSM-5: effect of organosilanes on the catalyst properties and performance in the catalytic fast pyrolysis of biomass. Microporous Mesoporous Mater 274, 190-197.

[57] Ren, X.Y., Cao, J.P., Zhao, X.Y., Yang, Z., Liu, S.N., Wei, X.Y., 2018. Enhancement of aromatic products from catalytic fast pyrolysis of lignite over hierarchical HZSM-5 by piperidine-assisted desilication. ACS Sustain. Chem. Eng. 6(2), 1792-1802.

[58] Serrano, D.P., Escola, J.M., Pizarro, P., 2013. Synthesis strategies in the search for hierarchical zeolites. Chem. Soc. Rev. 42(9), 4004 4035.

[59] Shao, S., Zhang, H., Shen, D., Xiao, R., 2016. Enhancement of hydrocarbon production and catalyst stability during catalytic conversion of biomass pyrolysis-derived compounds over hierarchical HZSM-5. RSC Adv. 6(50), 44313-44320.

[60] Shi, Y., Xing, E., Wu, K., Wang, J., Yang, M., Wu, Y., 2017. Recent progress on upgrading of bio-oil to hydrocarbons over metal/zeolite bifunctional catalysts. Catal. Sci. Technol. 7(12), 2385-2415.

[61] Soltanian, S., Aghbashlo, M., Almasi, F., Hosseinzadeh-Bandbafha, H., Nizami, A.-S., Ok, Y.S., Lam, S.S., Tabatabaei, M., 2020. A critical review of the effects of pretreatment methods on the exergetic aspects of lignocellulosic biofuels. Energy Convers. Manag. 212, 112792.

[62] Soltanian, S., Aghbashlo, M., Farzad, S., Tabatabaei, M., Mandegari, M., Görgens, J.F., 2019. Exergoeconomic analysis of lactic acid and power cogeneration from sugarcane residues through a biorefinery approach. Renew. Energy 143, 872-889.

[63] Stanton, A.R., Iisa, K., Mukarakate, C., Nimlos, M.R., 2018. Role of biopolymers in the deactivation of ZSM-5 during catalytic fast pyrolysis of biomass. ACS Sustain. Chem. Eng. 6(8), 10030-10038.

[64] Sun, L., Zhang, X., Chen, L., Zhao, B., Yang, S., Xie, X., 2016. Comparision of catalytic fast pyrolysis of biomass to aromatic hydrocarbons over ZSM-5 and Fe/ZSM-5 catalysts. J. Anal. Appl. Pyrolysis 121, 342-346.

[65] Svelle, S., Sommer, L., Barbera, K., Vennestrøm, P.N., Olsbye, U., Lillerud, K.P., Bordiga, S., Pan, Y.-H., Beato, P., 2011. How defects and crystal morphology control the effects of desilication. Catal. Today 168(1), 38-47.

[66] Tabatabaei, M., Soltanian, S., Aghbashlo, M., Nizami, A.-S., 2019 Fast pyrolysis of biomass: Advances in science and technology: A book review. J Clean. Prod. 213, 1411-1413. 
[67] Tan, Y., Abdullah, A., Hameed, B., 2018. Catalytic fast pyrolysis of durian rind using silica-alumina catalyst: Effects of pyrolysis parameters. Bioresour. Technol. 264, 198-205.

[68] Tang, S., Zhang, C., Xue, X., Pan, Z., Wang, D., Zhang, R., 2019. Catalytic pyrolysis of lignin over hierarchical HZSM-5 zeolites prepared by post-treatment with alkaline solutions. J. Anal. Appl. Pyrolysis 137, 86-95.

[69] Veses, A., Puértolas, B.a., López, J.M., Callén, M.S., Solsona, B., García, T., 2016. Promoting deoxygenation of bio-oil by metal-loaded hierarchical ZSM-5 zeolites. ACS Sustain. Chem. Eng. 4(3), 1653-1660.

[70] Wang, F., Zhou, M.-X., Yang, X.-h., Gao, L.-j., Xiao, G.-m., 2017. The effect of hierarchical pore architecture on one-step catalytic aromatization of glycerol: Reaction routes and catalytic performances. Mol. Catal. 432, 144-154.

[71] Wang, J., Zhong, Z., Ding, K., Zhang, B., Deng, A., Min, M., Chen, P., Ruan, R., 2017. Successive desilication and dealumination of HZSM-5 in catalytic conversion of waste cooking oil to produce aromatics. Energy Convers. Manag. 147, 100-107.

[72] Wang, W., Luo, Z., Li, S., Xue, S., Sun, H., 2020. Novel micromesoporous composite ZSM-5 catalyst for aromatics production by catalytic fast pyrolysis of lignin residues. Catalysts 10(4), 378.

[73] Xiao, W., Wang, F., Xiao, G., 2015. Performance of hierarchical HZSM5 zeolites prepared by $\mathrm{NaOH}$ treatments in the aromatization of glycerol. RSC Adv. 5(78), 63697-63704.

[74] Zang, Y., Dong, X., Ping, D., Geng, J., Dang, H., 2018. Green routes for the synthesis of hierarchical HZSM-5 zeolites with low $\mathrm{SiO}_{2} / \mathrm{Al}_{2} \mathrm{O}_{3}$ ratios for enhanced catalytic performance. Catal. Commun. 113, 51-54.

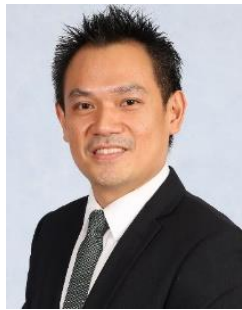

Dr. Su Shiung Lam holds a $\mathrm{PhD}$ in Chemical Engineering from the Cambridge University, and is currently an Associate Professor at the Institute of Tropical Aquaculture and Fisheries (AKUATROP) of the Universiti Malaysia Terengganu. He leads a research group working mainly on Chemical \& Environmental Engineering, focusing on Waste Management, Thermal Process (Pyrolysis, Gasification, Microwave Heating), and Waste \& Biomass Utilization. $\mathrm{He}$ is active on research, development, optimization, and application of thermal technology (especially pyrolysis).

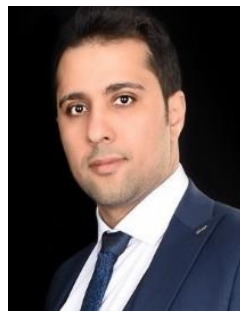

Salman Soltanian holds a master degree in Mechanical Engineering (Energy Conversion) from the Sharif University of Technology, and is currently a $\mathrm{PhD}$ candidate at the Universiti Malaysia Terengganu. Salman`s research is mainly focused on catalytic thermochemical pathways of biofuels production. He is in particular involved in research on catalytic behaviour of hierarchical zeolites during fast catalytic pyrolysis.
[75] Zhang, B., Zhang, J., Zhong, Z., Zhang, Y., Song, M., Wang, X., Ding, K., Ruan, R., 2018a. Conversion of poultry litter into bio-oil by microwave-assisted catalytic fast pyrolysis using microwave absorbent and hierarchical ZSM-5/MCM-41 catalyst. J. Anal. Appl. Pyrolysis 130, 233-240.

[76] Zhang, B., Zhong, Z., Li, T., Xue, Z., Wang, X., Ruan, R., 2018b. Biofuel production from distillers dried grains with solubles (DDGS) co-fed with waste agricultural plastic mulching films via microwaveassisted catalytic fast pyrolysis using microwave absorbent and hierarchical ZSM-5/MCM-41 catalyst. J. Anal. Appl. Pyrolysis 130, $1-7$.

[77] Zhang, J., Choi, Y.S., Shanks, B.H., 2016. Catalytic deoxygenation during cellulose fast pyrolysis using acid-base bifunctional catalysis. Catal. Sci. Technol. 6(20), 7468-7476.

[78] Zhang, Z., Cheng, H., Chen, H., Chen, K., Lu, X., Ouyang, P., Fu, J., 2018a. Enhancement in the aromatic yield from the catalytic fast pyrolysis of rice straw over hexadecyl trimethyl ammonium bromide modified hierarchical HZSM-5. Bioresour. Technol. 256, 241-246.

[79] Zhang, Z., Cheng, H., Chen, H., Li, J., Chen, K., Lu, X., Ouyang, P., $\mathrm{Fu}$, J., 2018b. Catalytic fast pyrolysis of rice straw to aromatics over hierarchical HZSM-5 treated with different organosilanes. Energ. Fuel. 33(1), 307-312.

[80] Zhou, J., Hua, Z., Liu, Z., Wu, W., Zhu, Y., Shi, J., 2011. Direct synthetic strategy of mesoporous ZSM-5 zeolites by using conventional block copolymer templates and the improved catalytic properties. ACS Catal. 1(4), 287-291.

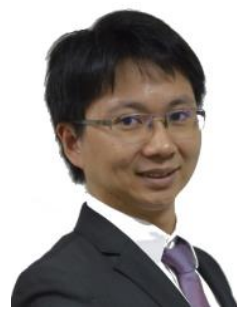

Dr. Lee Chern Leing is a lecturer in the Chemical Engineering discipline at the Monash University Malaysia. He received his $\mathrm{PhD}$ from the University of Cambridge, United Kingdom. He is a registered professional engineer in Malaysia and he leads a research group which is mainly working on the Colloid Science and Polymer. His research interests include Surface and Interface Science, Physics of Multiphase Flows and Waste Management. 